\title{
Expectations Traps and Coordination Failures: Selecting among Multiple Discretionary Equilibria
}

\author{
Richard Dennis \\ Federal Reserve Bank of San Francisco \\ Tatiana Kirsanova \\ University of Exeter
}

August 2010

Working Paper 2010-02

http://www.frbsf.org/publications/economics/papers/2010/wp10-02bk.pdf

The views in this paper are solely the responsibility of the authors and should not be interpreted as reflecting the views of the Federal Reserve Bank of San Francisco or the Board of Governors of the Federal Reserve System. 


\title{
Expectations Traps and Coordination Failures: Selecting among Multiple Discretionary Equilibria*
}

\author{
Richard Dennis ${ }^{\dagger}$ \\ Federal Reserve Bank of San Francisco
}

\author{
Tatiana Kirsanova \\ University of Exeter
}

August 24, 2010

\begin{abstract}
Discretionary policymakers cannot manage private-sector expectations and cannot coordinate the actions of future policymakers. As a consequence, expectations traps and coordination failures can occur and multiple equilibria can arise. To utilize the explanatory power of models with multiple equilibria it is first necessary to understand how an economy arrives to a particular equilibrium. In this paper, we employ notions of learnability, self-enforceability, and properness to motivate and develop a suite of equilibrium selection criteria. Central among these criteria are whether the equilibrium is learnable by private agents and jointly learnable by private agents and the policymaker. We use two New Keynesian policy models to identify the strategic interactions that give rise to multiple equilibria and to illustrate our equilibrium selection methods. Importantly, unless the Pareto-preferred equilibrium is learnable by private agents, we find little reason to expect coordination on that equilibrium.

Keywords: Discretionary policymaking, multiple equilibria, coordination, equilibrium selection.

JEL Classification: E52, E61, C62, C73.
\end{abstract}

\footnotetext{
*We would like to thank seminar participants at the University of Exeter, the Australian National University, the University of New South Wales, and Monash University, and participants at the 2010 Computing in Economics and Finance Conference for comments. The views expressed in this paper do not necessarily reflect those of the Federal Reserve Bank of San Francisco or the Federal Reserve System.

${ }^{\dagger}$ Address for Correspondence: Economic Research, Mail Stop 1130, Federal Reserve Bank of San Francisco, 101 Market St, CA 94105, USA. Email: richard.dennis@sf.frb.org.
} 


\section{Introduction}

Discretionary policymakers can fall foul of expectations traps and coordination failures. When private agents are forward-looking their expectations, shaped by anticipations about future policy, can influence importantly how policy today is conducted. The discretionary policymaker's Achilles heel is that when formulating policy it is unable to manage private sector expectations, and this inability, although essential for time-consistent policymaking, leaves ajar the door to multiple equilibria. When expectations cannot be managed, private agents can form expectations that, although unwelcome from the policymaker's perspective, lead private agents to react in a manner that traps the policymaker into implementing a policy that validates those expectations. The trap is closed when a policy that renders those unwelcome expectations without foundation is more costly and hence less attractive to the discretionary policymaker than a policy that accommodates them.

The fact that multiple equilibria produced by the policymaker's inability to manage private sector expectations can beset discretionary control problems is troublesome, yet hugely important. Troublesome, because efforts to solve or mitigate the time-consistency problem associated with optimal policymaking rely invariably on there being a unique discretionary equilibrium. A Rogoff-style (Rogoff, 1985) approach of delegating objectives to a discretionary policymaker (as per Jensen (2002) and Walsh (2003), among others) is unlikely to be successful unless it also solves the coordination problem. Similarly, to the extent that an optimal contract (Walsh, 1995) can successfully overcome the time-consistency problem, it too should address the coordination problem. Important, because it means that discretionary

policy behavior can be considerably richer and more varied than is commonly appreciated, with switches among equilibria becoming a potential source of economic volatility. Moreover, because the mechanisms that produce multiple equilibria involve the strategic interactions between agents over time, they are not precluded by linear constraints and quadratic objectives. As a consequence, much research analyzing discretionary policymaking since Kydland and Prescott (1977) may have inadvertently considered only one of several equilibria, potentially overlooking essential aspects of discretionary policy behavior.

It is not unusual for economies to transition between periods of high and low inflation, a phenomenon that expectations traps have the potential to explain (Albanesi, Chari, and Christiano, 2003). Similarly, transitions from one equilibrium to another offers an explanation for policy regime changes, like those analyzed by Davig and Leeper (2006). Accordingly, an 
explanation for the change in U. S. inflation behavior between the 1970s and the 1980s could be that Volcker's appointment to Federal Reserve Chairman served to coordinate expectations and behavior, switching the economy from one discretionary equilibrium to another. However, in order to utilize the explanatory power of multiple equilibria it is necessary to first consider how an economy arrives at a particular equilibrium. In the words of Benhabib and Farmer (1999, pp. 438), "in any model with multiple equilibria one must address the issue of how an equilibrium comes about".

In this paper, we study multiple equilibria in infinite-horizon linear-quadratic discretionary control problems. We describe the control problem facing the discretionary policymaker and, drawing on Oudiz and Sachs (1985) and Currie and Levine (1985, 1993), reinterpret the control problem as a dynamic game between policymakers at different points in time. An important aspect of this game is that within a period the policymaker is a (Stackelberg) leader with respect to private agents. Feedback equilibria to the discretionary control problem correspond to Markov-perfect Stackelberg-Nash equilibria to the dynamic game. We show how strategic interaction among current and future policymakers, operating through endogenous state variables and private sector expectations, leads to a form of strategic complementarity (Cooper and John, 1988) and makes expectations traps and coordination failures possible.

We approach the coordination problem inherent in equilibrium selection from three angles. First, we consider eductive learning as a coordinating mechanism for equilibrium selection (Evans, 1986), drawing on the large literature that employs learning to analyze coordination in rational expectations models (Guesnerie and Woodford, 1992; Evans and Guesnerie, 1993; 2003; 2005; Evans and Honkapohja, 2001). With agents learning eductively, and allowing private agents and/or the policymaker to be learning, we develop three expectational stability conditions whose satisfaction determines whether private agents and/or the policymaker might reasonably learn and coordinate on a particular equilibrium. Among these three sets of stability conditions, we show that the key conditions are those indicating whether an equilibrium is learnable by private agents in isolation and by private agents and the policymaker jointly. Second, we consider whether the potential for non-cooperative coalitions to form might effectively rule out some equilibria (Bernheim, Peleg, and Whinston, 1987). Pursuing this idea, we examine whether the Nash equilibria we obtain are self-enforceable. Third, we consider whether the number and nature of the equilibria we find is sensitive to perturbations to the model. Specifically, in the models that we analyze, we find it plausible that privatesector expectations of future aggregate inflation might be formed using outdated information 
and implausible that agents could coordinate on equilibria whose existence does not survive perturbations to this information set.

To illustrate equilibrium multiplicity and an approach to equilibrium selection, we analyze two New Keynesian models. The first model is a government-debt model adapted from Leeper (1991) by Blake and Kirsanova (2007). The second model is a simplified version of the dynamic stochastic general equilibrium model developed by Christiano, Eichenbaum, and Evans (2005) and Smets and Wouters (2007). In each model, the task confronting the policymaker is to stabilize inflation without impacting unduly the real economy. Inflation, in these models, is determined by the expected path of real marginal costs, so the policy challenge is to generate an appropriate path for real marginal costs. Since inflation depends on the entire expected path for real marginal costs while the discretionary policymaker can choose only today's policy, the policy chosen today depends necessarily on expected future policy. At the same time, the decisions that future policymakers make depend materially on the economic circumstances that they find themselves in, and hence on the choices previous policymakers have made. This interaction between policymakers over time produces coordination failure and leads to multiple equilibria.

Our research is related to several other papers. King and Wolman (2004) show that multiple discretionary equilibria can arise in a New Keynesian policy model if there is strategiccomplementarity in firms' pricing. In their model, non-linearities cause there to be multiple point-in-time equilibria and the strategic complementarity introduces a coordination problem. ${ }^{1} \quad$ Unlike King and Wolman (2004), the multiplicity that we analyze does not require non-linearity. Our paper is also related to Albanesi, Chari, and Christiano (2003), who show that a modified version of the Lucas and Stokey (1983) cash-credit model can have multiple discretionary equilibria when some firms have sticky prices, and to Ortigueira and Pereira (2009), who analyze time-consistent policymaking when the Stackelberg player is a fiscal authority and also find multiple discretionary equilibria. Finally, our paper builds on Blake and Kirsanova (2007), who first showed the existence of multiple discretionary equilibria in the linear-quadratic context.

The remainder of the paper is structured as follows. In Section 2, we describe the linearquadratic discretionary control problem, provide a game theoretic interpretation, define a

\footnotetext{
${ }^{1}$ Interestingly, Dotsey and Hornstein (2008) and van Zandweghe and Wolman (2010) show that the multiplicity highlighted by King and Wolman (2004) does not emerge if the policy instrument is the nominal instrument, rather than nominal money balances, or if price rigidity is modeled in terms of Calvo-contracts, rather than two-period Taylor-contracts, respectively.
} 
symmetric Markov-perfect Stackelberg-Nash equilibrium, and show how such equilibria can be obtained. In Section 3, we outline how expectational stability criteria associated with eductive learning, notions of non-cooperative coalitions, and model perturbation can be used to select among multiple equilibria. In Section 4, we analyze two New Keynesian policy models, show that they each possess multiple equilibria, and illustrate how the selection criteria can be employed. Section 5 concludes.

\section{The discretionary control problem}

In this section, we outline the control problem facing a discretionary policymaker. We then reinterpret this control problem as a non-cooperative dynamic game and show that the standard optimal discretionary policy is a symmetric Markov-perfect Nash equilibrium of a dynamic game in which the policymaker is a Stackelberg leader and private agents are followers. To make explicit the game's leadership structure, we call this equilibrium a symmetric Markov-perfect Stackelberg-Nash equilibrium. Finally, we show that solving for a symmetric Markov-perfect Stackelberg-Nash equilibrium in this game requires solving a particular fix-point problem.

\subsection{Constraints and objectives}

The economic environment is one in which $n_{1}$ predetermined variables, $\mathbf{x}_{t}$, and $n_{2}$ nonpredetermined variables, $\mathbf{y}_{t}, t=0,1, \ldots, \infty$, evolve over time according to

$$
\begin{aligned}
\mathbf{x}_{t+1} & =\mathbf{A}_{11} \mathbf{x}_{t}+\mathbf{A}_{12} \mathbf{y}_{t}+\mathbf{B}_{1} \mathbf{u}_{t}+\mathbf{v}_{\mathbf{x} t+1}, \\
\mathrm{E}_{t} \mathbf{y}_{t+1} & =\mathbf{A}_{21} \mathbf{x}_{t}+\mathbf{A}_{22} \mathbf{y}_{t}+\mathbf{B}_{2} \mathbf{u}_{t},
\end{aligned}
$$

where $\mathbf{u}_{t}$ is a $p \times 1$ vector of control variables, $\mathbf{v}_{\mathbf{x} t} \sim i . i . d .[\mathbf{0}, \boldsymbol{\Sigma}]$ is an $v \times 1\left(1 \leq v \leq n_{1}\right)$ vector of white-noise innovations, and $\mathrm{E}_{t}$ is the mathematical expectations operator conditional upon period $t$ information. Equations (1) and (2) capture aggregate constraints and technologies and the behavior (aggregate first-order conditions) of private agents. For their part, private agents are comprised of households and firms who are ex ante identical, respectively, infinitely lived, and atomistic. The matrices $\mathbf{A}_{11}, \mathbf{A}_{12}, \mathbf{A}_{21}, \mathbf{A}_{22}, \mathbf{B}_{1}$, and $\mathbf{B}_{2}$ are conformable with $\mathbf{x}_{t}$, $\mathbf{y}_{t}$, and $\mathbf{u}_{t}$ as necessary and contain the parameters that govern preferences and technologies. Importantly, the matrix $\mathbf{A}_{22}$ is assumed to have full rank.

In addition to private agents, the economy is populated by a large player, a policymaker. 
For each period $t$, the period- $t$ policymaker's objectives are described by the loss function

$$
L_{t}=\mathrm{E}_{t} \sum_{k=t}^{\infty} \beta^{(k-t)}\left[\mathbf{z}_{k}^{\prime} \mathbf{W} \mathbf{z}_{k}+2 \mathbf{z}_{k}^{\prime} \mathbf{U} \mathbf{u}_{k}+\mathbf{u}_{k}^{\prime} \mathbf{Q} \mathbf{u}_{k}\right]
$$

where $\beta \in(0,1)$ is the discount factor and $\mathbf{z}_{k}=\left[\begin{array}{ll}\mathbf{x}_{k}^{\prime} & \mathbf{y}_{k}^{\prime}\end{array}\right]^{\prime}$. We assume that the weighting matrices $\mathbf{W}$ and $\mathbf{Q}$ are symmetric and, to ensure that the loss function is convex, that the matrix $\left[\begin{array}{ll}\mathbf{W} & \mathbf{U} \\ \mathbf{U}^{\prime} & \mathbf{Q}\end{array}\right]$ is positive semi-definite. ${ }^{2}$ We assume that the policymaker is a Stackelberg leader and that private agents are followers; we further assume that the policymaker does not have access to a commitment technology and that policy is conducted under discretion. ${ }^{3}$ With policy conducted under discretion, the policymaker sets its control variables, $\mathbf{u}_{t}$, each period to minimize equation (3), taking the state, $\mathbf{x}_{t}$, and the decision rules of all future agents as given. Since the policymaker is a Stackelberg leader, the period- $t$ policy decision is formulated taking equation (2) as well as equation (1) into account.

The control problem described above has many of the characteristics of an infinite horizon non-cooperative dynamic game, and is commonly viewed as such. Following Oudiz and Sachs (1985), Currie and Levine (1985), and Cohen and Michel (1988), the strategic players in the game are the (infinite) sequence of policymakers with private agents behaving competitively. Although individual private agents are not strategic players in aggregate they are not inconsequential. Private agents are important because private-sector expectations are the conduit through which strategic interaction between current and future policymakers occurs. In this decision problem, policy behavior is described by a policy strategy, private-agent behavior is described by a private sector strategy, the expectations operator $\left(\mathrm{E}_{t}\right)$ and policy loss (payoff) are induced by the policy and private sector strategies, and the equilibrium that we seek to analyze is a symmetric Markov-perfect Stackelberg-Nash equilibrium.

\subsection{Some useful definitions and equilibrium concepts}

In the previous section we emphasized that the discretionary control problem can be modeled as a non-cooperative dynamic game, with the decisions of the policymaker and of private agents

\footnotetext{
${ }^{2}$ It is standard to assume that the weighting matrices, $\mathbf{W}$ and $\mathbf{Q}$, are symmetric positive semi-definite and symmetric positive definite, respectively (see Anderson, Hansen, McGrattan, and Sargent (1996), for example). However, since many economic applications involve a loss function that places no penalty on the control variables, we note that the requirement of $\mathbf{Q}$ being positive definite can be weakened to $\mathbf{Q}$ being positive semi-definite if additional assumptions about other system matrices are met (Clements and Wimmer, 2003).

${ }^{3}$ Events within a period occur as follows. After observing the state, $\mathbf{x}_{t}$, decisions are made first by the incumbent policymaker and subsequently by private agents. At the end of the period the shocks $\mathbf{v}_{\mathbf{x} t+1}$ are realized.
} 
taking the form of strategies. Further, we noted that because the policymaker is assumed to be a Stackelberg leader the discretionary equilibrium that we are interested in is a symmetric Markov-perfect Stackelberg-Nash equilibrium. We now make these terms precise. ${ }^{4}$

Definition 1 A policy strategy $\mathbf{S}$ is a sequence of policy rules $\left\{\mathbf{F}_{t}\right\}_{0}^{\infty}$, where $\mathbf{F}_{t}$ is a function that maps $\left\{\mathbf{x}_{t}\right\}_{0}^{t}$ to $\mathbf{u}_{t}$. A policy strategy is said to be a Markov policy strategy if and only if each policy rule $\mathbf{F}_{t}$ is a function that maps $\mathbf{x}_{t}$ to $\mathbf{u}_{t}$. We denote by $\mathbf{S}_{-t}$ the sequence of policy rules $\left\{\mathbf{F}_{s}\right\}_{0}^{\infty}$ excluding $\mathbf{F}_{t}$.

Definition 2 A private sector strategy $\mathbf{T}$ is a sequence of decision rules $\left\{\mathbf{H}_{t}\right\}_{0}^{\infty}$, where $\mathbf{H}_{t}$ is a function that maps $\left\{\mathbf{x}_{t}\right\}_{0}^{t}$ to $\mathbf{y}_{t}$. A private sector strategy is said to be a Markov private sector strategy if and only if each decision rule $\mathbf{H}_{t}$ is a function that maps $\mathbf{x}_{t}$ to $\mathbf{y}_{t}$. We denote by $\mathbf{T}_{-t}$ the sequence of decision rules $\left\{\mathbf{H}_{s}\right\}_{0}^{\infty}$ excluding $\mathbf{H}_{t}$.

Definition 3 A policy strategy $\mathbf{S}$ is a Stackelberg-Nash equilibrium if for every decision period $t$ : i) $\mathbf{F}_{t}$ minimizes equation (3) subject to equations (1) and (2) and $\mathbf{x}_{t}$ known, taking $\mathbf{S}_{-t}$ and $\mathbf{T}_{-t}$ as given; and ii) $\mathbf{H}_{t}$ satisfies equations (1) and (2), taking $\mathbf{S}$ and $\mathbf{T}_{-t}$, as given.

Definition 4 A policy strategy $\mathbf{S}$ is a perfect Stackelberg-Nash equilibrium if for every decision period $t$ and any history $\left\{\mathbf{F}_{s}, \mathbf{H}_{s}\right\}_{0}^{t-1}$ : i) $\mathbf{F}_{t}$ minimizes equation (3) subject to equations (1) and (2) and $\mathbf{x}_{t}$ known, taking $\mathbf{S}_{-t}$ and $\mathbf{T}_{-t}$ as given; and ii) $\mathbf{H}_{t}$ satisfies equations (1) and (2), taking $\mathbf{S}$ and $\mathbf{T}_{-t}$ as given.

A perfect Stackelberg-Nash equilibrium is time-consistent because it is subgame perfect. However, the strategies that characterize equilibrium are not necessarily Markov strategies and, as a consequence, trigger-strategy equilibria, and other equilibria supported by threats and punishments are not ruled out. The sustainable equilibria studied by Chari and Kehoe (1990), Ireland (1997), and Kurozumi (2008) as well as the "reputational" equilibria examined by Barro and Gordon (1983) are all examples of perfect Stackelberg-Nash equilibria.

Definition 5 A policy strategy $\mathbf{S}$ is a Markov-perfect Stackelberg-Nash equilibrium if restricting $\mathbf{S}$ to be a Markov policy strategy and $\mathbf{T}$ to be a Markov private sector strategy, for every

\footnotetext{
${ }^{4}$ Although the discretionary control problem described in section 2.1 is standard in the monetary policy literature (it is the formulation used by Clarida, Galí, and Gertler (1999), for example) there are other notions of discretion in the literature. These different notions of discretion are associated either with different dynamic games or with different equilibrium concepts. Cohen and Michel (1988), de Zeeuw and van der Ploeg (1991), and Chow (1997, chapter 6) provide useful discussions.
} 
time period $t$ and any history of Markov policy and decision rules $\left\{\mathbf{F}_{s}, \mathbf{H}_{s}\right\}_{0}^{t-1}$ : i) $\mathbf{F}_{t}$ minimizes equation (3) subject to equations (1) and (2) and $\mathbf{x}_{t}$ known, taking $\mathbf{S}_{-t}$ and $\mathbf{T}_{-t}$ as given; and ii) $\mathbf{H}_{t}$ satisfies equations (1) and (2), taking $\mathbf{S}$ and $\mathbf{T}_{-t}$ as given.

Definition 6 A policy strategy $\mathbf{S}$ is a symmetric Markov-perfect Stackelberg-Nash equilibrium if and only if: i) $\mathbf{S}$ is a Markov-perfect Stackelberg-Nash equilibrium in which $\mathbf{F}_{t}=\mathbf{F}, \forall t$; and ii) $\mathbf{T}$ is a Markov private sector strategy in which $\mathbf{H}_{t}=\mathbf{H}, \forall t$.

\subsection{Characterizing equilibrium}

For the decision problem summarized by equations (1)-(3), we now describe the equilibrium conditions that characterize a symmetric Markov-perfect Stackelberg-Nash equilibrium, focusing on equilibria for which the decision rules are linear in the state vector.

First, if a symmetric Markov-perfect Stackelberg-Nash equilibrium exists, then in this equilibrium the behavior of the policymaker and private agents in all states, $\mathbf{x}_{t}$, and in all decision periods, $t=0, \ldots, \infty$, is described by the linear rules

$$
\begin{aligned}
& \mathbf{u}_{t}=\mathbf{F} \mathbf{x}_{t}, \\
& \mathbf{y}_{t}=\mathbf{H} \mathbf{x}_{t},
\end{aligned}
$$

respectively. In this equilibrium, the law-of-motion for the predetermined variables is given by

$$
\mathbf{x}_{t+1}=\mathbf{M} \mathbf{x}_{t}+\mathbf{v}_{\mathbf{x} t+1}
$$

where the spectral radius of $\mathbf{M}$ is less than $\beta^{-\frac{1}{2}}$. Further, since the loss function is quadratic and the constraints are linear, the payoff to the policymaker in period $t$ that corresponds to these rules is summarized by the quadratic state-contingent value function

$$
V\left(\mathbf{x}_{t}\right)=\mathbf{x}_{t}^{\prime} \mathbf{V} \mathbf{x}_{t}+d
$$

where $\mathbf{V}$ is symmetric positive semi-definite. Importantly, because the policy rule, $\mathbf{F}$, and the decision rule, $\mathbf{H}$, in a symmetric Markov-perfect Stackelberg-Nash equilibrium apply in all states, the subgames one needs to consider when solving for a symmetric Markov-perfect Stackelberg-Nash equilibrium are those indexed only by time.

Second, if a symmetric Markov-perfect Stackelberg-Nash equilibrium exists for the subgame beginning in period $t+1$, then one can condition the subgame beginning in period $t$ on the $\overline{\mathbf{H}}$, $\overline{\mathbf{F}}, \overline{\mathbf{M}}, \overline{\mathbf{V}}$, and $\bar{d}$ that characterize the equilibrium of the subgame beginning in period $t+1$. 
Thus, the decision problem facing the policymaker in the subgame beginning in period $t$ is to choose a rule for setting $\mathbf{u}_{t}$ in order to minimize

$$
\begin{aligned}
\mathbf{x}_{t}^{\prime} \mathbf{V} \mathbf{x}_{t}+d= & \mathbf{x}_{t}^{\prime} \mathbf{W}_{11} \mathbf{x}_{t}+\mathbf{x}_{t}^{\prime} \mathbf{W}_{12} \mathbf{y}_{t}+\mathbf{y}_{t}^{\prime} \mathbf{W}_{21} \mathbf{x}_{t}+\mathbf{y}_{t}^{\prime} \mathbf{W}_{22} \mathbf{y}_{t}+2 \mathbf{x}_{t}^{\prime} \mathbf{U}_{1} \mathbf{u}_{t}+2 \mathbf{y}_{t}^{\prime} \mathbf{U}_{2} \mathbf{u}_{t}+\mathbf{u}_{t}^{\prime} \mathbf{Q} \mathbf{u}_{t} \\
& +\beta \mathrm{E}_{t}\left(\mathbf{x}_{t+1}^{\prime} \overline{\mathbf{V}} \mathbf{x}_{t+1}+\bar{d}\right)
\end{aligned}
$$

subject to equations (1) and (2) and

$$
\begin{aligned}
\mathbf{u}_{t+1} & =\overline{\mathbf{F}} \mathbf{x}_{t+1}, \\
\mathbf{y}_{t+1} & =\overline{\mathbf{H}} \mathbf{x}_{t+1},
\end{aligned}
$$

and $\mathbf{x}_{t}$ known. Importantly, although $\overline{\mathbf{H}}$ and $\overline{\mathbf{V}}$ are functions of $\overline{\mathbf{F}}$, the problem's structure means that $\overline{\mathbf{F}}$ does not have a separate, explicit, effect on the current period payoff, $V\left(\mathbf{x}_{t}\right)=$ $\mathbf{x}_{t}^{\prime} \mathbf{V} \mathbf{x}_{t}+d$. Consequently, as this decision problem is formulated, equation (7) does not bind as a separate constraint.

Using equation (8) to form $\mathrm{E}_{t} \mathbf{y}_{t+1}$, substituting the resulting expression into equation (2), and exploiting equation (1), we obtain the aggregate private-sector reaction function

$$
\mathbf{y}_{t}=\mathbf{J} \mathbf{x}_{t}+\mathbf{K} \mathbf{u}_{t}
$$

where

$$
\begin{aligned}
\mathbf{J} & =\left(\mathbf{A}_{22}-\overline{\mathbf{H}} \mathbf{A}_{12}\right)^{-1}\left(\overline{\mathbf{H}} \mathbf{A}_{11}-\mathbf{A}_{21}\right) \\
\mathbf{K} & =\left(\mathbf{A}_{22}-\overline{\mathbf{H}} \mathbf{A}_{12}\right)^{-1}\left(\overline{\mathbf{H}} \mathbf{B}_{1}-\mathbf{B}_{2}\right)
\end{aligned}
$$

Provided $\operatorname{rank}(\mathbf{K}) \neq \mathbf{0}$, equation (9) implies that the period- $t$ policymaker is a Stackelberg leader with respect to the period- $t$ private sector. Then, substituting equation (9) into equations (6) and (1), the decision problem facing the policymaker in the subgame beginning in period $t$ is to choose a rule for setting $\mathbf{u}_{t}$ in order to minimize

$$
\mathbf{x}_{t}^{\prime} \mathbf{V} \mathbf{x}_{t}+d=\mathbf{x}_{t}^{\prime} \widehat{\mathbf{W}} \mathbf{x}_{t}+2 \mathbf{x}_{t}^{\prime} \widehat{\mathbf{U}} \mathbf{u}_{t}+\mathbf{u}_{t}^{\prime} \widehat{\mathbf{Q}} \mathbf{u}_{t}+\beta \mathrm{E}_{t}\left(\mathbf{x}_{t+1}^{\prime} \overline{\mathbf{V}} \mathbf{x}_{t+1}+\bar{d}\right)
$$

subject to

$$
\mathbf{x}_{t+1}=\widehat{\mathbf{A}} \mathbf{x}_{t}+\widehat{\mathbf{B}} \mathbf{u}_{t}+\mathbf{v}_{\mathbf{x} t+1}
$$


where

$$
\begin{aligned}
\widehat{\mathbf{W}} & =\mathbf{W}_{11}+\mathbf{W}_{12} \mathbf{J}+\mathbf{J}^{\prime} \mathbf{W}_{21}+\mathbf{J}^{\prime} \mathbf{W}_{22} \mathbf{J} \\
\widehat{\mathbf{U}} & =\mathbf{W}_{12} \mathbf{K}+\mathbf{J}^{\prime} \mathbf{W}_{22} \mathbf{K}+\mathbf{U}_{1}+\mathbf{J}^{\prime} \mathbf{U}_{2} \\
\widehat{\mathbf{Q}} & =\mathbf{Q}+\mathbf{K}^{\prime} \mathbf{W}_{22} \mathbf{K}+2 \mathbf{K}^{\prime} \mathbf{U}_{2} \\
\widehat{\mathbf{A}} & =\mathbf{A}_{11}+\mathbf{A}_{12} \mathbf{J} \\
\widehat{\mathbf{B}} & =\mathbf{B}_{1}+\mathbf{A}_{12} \mathbf{K} .
\end{aligned}
$$

Conditional on $\overline{\mathbf{H}}$ and $\overline{\mathbf{V}}$ (and $\overline{\mathbf{F}}$ ), equations (12) and (13) describe a standard linearquadratic dynamic programming problem. To guarantee existence of a solution, we need $(\widehat{\mathbf{A}}, \widehat{\mathbf{B}})$ to be a controllable pair and $(\widehat{\mathbf{A}}, \widehat{\mathbf{W}})$ to be a detectable pair (Laub, 1979; Anderson, Hansen, McGrattan, and Sargent, 1996). Suppose that, for a given $\mathbf{J}$ and $\mathbf{K},(\widehat{\mathbf{A}}, \widehat{\mathbf{B}})$ is a controllable pair and $(\widehat{\mathbf{A}}, \widehat{\mathbf{W}})$ is a detectable pair, then the solution to the subgame beginning in period $t$ has the form of rules (4) and (5), with

$$
\begin{aligned}
\mathbf{F} & =-\left(\widehat{\mathbf{Q}}+\beta \widehat{\mathbf{B}}^{\prime} \overline{\mathbf{V}} \widehat{\mathbf{B}}\right)^{-1}\left(\widehat{\mathbf{U}}^{\prime}+\beta \widehat{\mathbf{B}}^{\prime} \overline{\mathbf{V}} \widehat{\mathbf{A}}\right) \\
\mathbf{0} & =\overline{\mathbf{H}} \mathbf{A}_{12} \mathbf{H}-\mathbf{A}_{22} \mathbf{H}+\overline{\mathbf{H}}\left(\mathbf{A}_{11}+\mathbf{B}_{1} \mathbf{F}\right)-\mathbf{A}_{21}-\mathbf{B}_{2} \mathbf{F} \\
\mathbf{V} & =\widehat{\mathbf{W}}+2 \widehat{\mathbf{U}} \mathbf{F}+\mathbf{F}^{\prime} \widehat{\mathbf{Q}} \mathbf{F}+\beta(\widehat{\mathbf{A}}+\widehat{\mathbf{B}} \mathbf{F})^{\prime} \overline{\mathbf{V}}(\widehat{\mathbf{A}}+\widehat{\mathbf{B}} \mathbf{F}) \\
d & =\beta \operatorname{tr}(\mathbf{V} \boldsymbol{\Sigma})+\beta \bar{d}
\end{aligned}
$$

From $\mathbf{F}$ and $\mathbf{H}$, the matrix $\mathbf{M}$ in the law-of-motion for the predetermined variables is then given by

$$
\mathbf{M}=\mathbf{A}_{11}+\mathbf{A}_{12} \mathbf{H}+\mathbf{B}_{1} \mathbf{F}
$$

Because $\overline{\mathbf{H}}, \overline{\mathbf{F}}, \overline{\mathbf{M}}, \overline{\mathbf{V}}$, and $\bar{d}$ represent a symmetric Markov-perfect Stackelberg-Nash equilibrium for the subgame beginning in period $t+1$, any fix-point of equations (19) - (23) in which $\mathbf{H}=\overline{\mathbf{H}}, \mathbf{F}=\overline{\mathbf{F}}, \mathbf{M}=\overline{\mathbf{M}}, \mathbf{V}=\overline{\mathbf{V}}$, and $d=\bar{d}$, such that $\mathbf{V}$ is symmetric positive semidefinite and $\left(\widehat{\mathbf{Q}}+\beta \widehat{\mathbf{B}}^{\prime} \mathbf{V} \widehat{\mathbf{B}}\right)$ has full rank, is a symmetric Markov-perfect Stackelberg-Nash equilibrium for the subgame beginning in period $t$.

Although an array of root-solving methods could be used to solve equations (19) - (23), economic applications invariably employ either the Backus and Driffill (1986) or the (closely related) Oudiz and Sachs (1985) methods, which are based on recursive iterations. 


\subsection{Implementability}

Having described the fix-point problem that a symmetric Markov-perfect Stackelberg-Nash equilibrium must satisfy, here we address the issue of whether an equilibrium can be implemented. Implementability is important because it relates whether an equilibrium can be brought about if policymakers pursue its associated policy strategy. Consistent with Dotsey and Hornstein (2008),

Definition 7 Let $\widetilde{\mathbf{A}}=\left[\begin{array}{ll}\mathbf{A}_{11}+\mathbf{B}_{1} \mathbf{F} & \mathbf{A}_{12} \\ \mathbf{A}_{21}+\mathbf{B}_{2} \mathbf{F} & \mathbf{A}_{22}\end{array}\right]$. A symmetric Markov-Perfect StackelbergNash equilibrium is said to be implementable, or, equivalently, a policy strategy, $\mathbf{S}$, is said to implement a symmetric Markov-perfect Stackelberg-Nash equilibrium, if: i) $(\mathbf{I}-\widetilde{\mathbf{A}}) \mathbf{z}^{*}=\mathbf{0}$ implies $\mathbf{z}^{*}=\mathbf{0}$; ii) $\left(\mathbf{H A}_{12}-\mathbf{A}_{22}\right)$ has full rank; and iii) $\widetilde{\mathbf{A}}$ has precisely $n_{2}$ eigenvalues with modulus greater than 1 .

Collectively these three conditions say that if a symmetric Markov-perfect StackelbergNash equilibrium to be implementable, then, when policy is conducted according to its associated strategy, $\mathbf{S}$, the model described by equations (1) and (2) must have: i) a unique steady state; ii) a unique point-in-time equilibrium; and iii) a unique rational expectations equilibrium.

It is frequently the case that a symmetric Markov-perfect Stackelberg-Nash equilibrium is not implementable - even when it is unique for a model — because the (Markov) policy strategy does not imply a unique rational expectations equilibrium. However, if a model happens to have one or more equilibria that is implementable, then these equilibria are notable because they can be brought to prevail if policymakers conduct policy according to their associated policy strategy, $\mathbf{S}$.

\section{Equilibrium selection}

Although we recognize that in many instances all equilibria may be of interest, because it strengthens a model's predictive content it is often desirable and advantageous to identify a single equilibrium (or a smaller set of equilibria) of interest, especially if one equilibrium stands out as a likely candidate for coordination. For example, as we shall see, although a model may have multiple equilibria, if the Pareto-preferred equilibrium is implementable, then one could reasonably expect the Pareto-preferred equilibrium to prevail. In this section, we introduce and discuss criteria that can be applied to reduce the set of equilibria and to possibly 
identify a unique equilibrium of interest. Specifically, we focus on three coordination/selection mechanisms: expectational stability (Evans, 1986), self-enforceability (Bernheim, Peleg, and Whinston, 1987), and properness (Myerson, 1978).

\subsection{Eductive learning and expectational stability}

Evans (1986) motivates expectational stability as a selection criterion in rational expectations models with multiple equilibria. Loosely speaking, a rational expectations equilibrium is expectationally stable if, following small deviations to the expectation formation process, the system returns to that equilibrium under a "natural revision rule". The relevant revision rule emerges naturally from the thought process whereby agents undertake to revise how they form expectations based on how those expectations would effect the actual economy, seeking to rationalize, or equate, a perceived law-of-motion with the actual law-of-motion. Although the revisions occur in meta-time, there is a close connection between expectational stability and real-time least-squares learnability of a rational expectations equilibrium (Marcet and Sargent, 1989; Evans and Honkapohja, 2001).

Like Evans (1986) and Evans and Guesnerie (2003, 2005), we view learning as a mechanism through which agents may coordinate on an equilibrium. Unlike these studies, however, the models we analyze are populated by both private agents and a policymaker, one or both of which may be learning. As a consequence, we analyze three learning problems and derive three expectational stability related conditions. In each case, the learning that we entertain is eductive in nature with agents revising their behavior in meta-time based on the outcomes of thought experiments. The notion of stability under learning that we consider is iterative expectational stability (IE-stability). ${ }^{5}$

Recall that a symmetric Markov-perfect Stackelberg-Nash equilibrium is characterized by $\{\mathbf{H}, \mathbf{F}, \mathbf{M}, \mathbf{V}, d\}$. Because $\mathbf{M}$ and $d$ follow immediately and uniquely from $\mathbf{F}, \mathbf{H}$, and $\mathbf{V}$, we implement the partitioning $\{\{\mathbf{H}, \mathbf{F}, \mathbf{V}\},\{\mathbf{M}, d\}\}$ and focus on $\{\mathbf{H}, \mathbf{F}, \mathbf{V}\}$ in what follows. Specifically, we consider:

1. Private sector learning, where we analyze whether private agents can learn $\mathbf{H}$, conditional on $\{\mathbf{F}, \mathbf{V}\}$.

2. Policymaker learning, where we analyze whether the policymaker can learn $\{\mathbf{F}, \mathbf{V}\}$, conditional on $\{\mathbf{H}\}$.

\footnotetext{
${ }^{5}$ See Evans (2001) for a very useful discussion of adaptive versus eductive learning and of expectational stability (E-stability) versus iterative expectational stability (IE-stability).
} 
3. Joint learning, where we analyze whether private agents and the policymaker can learn

$\{\mathbf{H}, \mathbf{F}, \mathbf{V}\}$ jointly.

\subsubsection{Preliminaries}

To place the three learning problems in a unified framework, let us denote by $\boldsymbol{\Phi}$ the object(s) to be learned. Thus, in the case where only private agents are learning $\boldsymbol{\Phi}=\{\mathbf{H}\}$. Then, to determine whether $\boldsymbol{\Phi}$ is learnable we construct and analyze the T-map that relates a perception of $\boldsymbol{\Phi}$, denoted $\overline{\boldsymbol{\Phi}}$, to an actual $\boldsymbol{\Phi}, \boldsymbol{\Phi}=T(\overline{\mathbf{\Phi}})$.

Definition 8 A fix-point, $\mathbf{\Phi}^{*}$, of the T-map, $\mathbf{\Phi}=T(\overline{\mathbf{\Phi}})$, is said to be IE-stable if

$$
\lim _{k \uparrow \infty} T^{k}(\overline{\mathbf{\Phi}})=\mathbf{\Phi}^{*}
$$

for all $\overline{\mathbf{\Phi}} \neq \mathbf{\Phi}^{*}$.

It follows that $\boldsymbol{\Phi}^{*}$ is IE-stable if and only if it is a stable fix-point of the difference equation

$$
\mathbf{\Phi}_{k+1}=T\left(\mathbf{\Phi}_{k}\right)
$$

where index $k$ denotes the step of the updating process. Similarly,

Definition 9 A fix-point, $\mathbf{\Phi}^{*}$, of the T-map, $\mathbf{\Phi}=T(\overline{\mathbf{\Phi}})$, is said to be locally IE-stable if

$$
\lim _{k \uparrow \infty} T^{k}(\overline{\mathbf{\Phi}})=\mathbf{\Phi}^{*}
$$

for all $\overline{\mathbf{\Phi}}$ about a neighborhood of $\mathbf{\Phi}^{*}$.

Let the derivative of the T-map be denoted $D T\left(\mathbf{\Phi}^{*}\right)$, then it is straightforward to prove the following Lemma.

Lemma 1 Assume that the derivative map, DT $\left(\mathbf{\Phi}^{*}\right)$, has no eigenvalues with modulus equal to 1. A fix-point, $\mathbf{\Phi}^{*}$, of the T-map, $\mathbf{\Phi}=T(\overline{\mathbf{\Phi}})$, is locally IE-stable if and only if all eigenvalues of the derivative map, DT $\left(\boldsymbol{\Phi}^{*}\right)$, have modulus less than 1.

Proof. Following Evans (1985), to analyze the local stability of equation (24) we linearize the equation about $\boldsymbol{\Phi}^{*}$. Using matrix calculus results from Magnus and Neudecker (1988, chapter 9) we obtain

$$
d\left(\operatorname{vec}\left(\mathbf{\Phi}_{k+1}\right)\right)=D T\left(\mathbf{\Phi}^{*}\right) d\left(\operatorname{vec}\left(\mathbf{\Phi}_{k}\right)\right)
$$


where $D T\left(\boldsymbol{\Phi}^{*}\right)=\partial\left(\operatorname{vec}\left(T\left(\boldsymbol{\Phi}^{*}\right)\right)\right) / \partial(v e c(\boldsymbol{\Phi}))^{\prime}$. Applying standard results for linear difference equations, if all of the eigenvalues of $D T\left(\mathbf{\Phi}^{*}\right)$ have modulus less than one, then $\boldsymbol{\Phi}^{*}$ is locally stable. In contrast, if one or more of the eigenvalues of $D T\left(\mathbf{\Phi}^{*}\right)$ have modulus greater than one, then $\mathbf{\Phi}^{*}$ is not locally stable.

\subsubsection{Eductive learning by private agents}

We begin with the case in which only private agents are learning and examine whether private agents can learn $\mathbf{H}$, given $\{\mathbf{F}, \mathbf{V}\}$. For a given policy rule, $\mathbf{u}_{t}=\mathbf{F} \mathbf{x}_{t}$, and a postulated private sector decision rule

$$
\mathbf{y}_{t}=\overline{\mathbf{H}} \mathbf{x}_{t}
$$

the actual private sector decision rule takes the form

$$
\mathbf{y}_{t}=\mathbf{H x}_{t}
$$

where

$$
\mathbf{H}=\left(\overline{\mathbf{H}} \mathbf{A}_{12}-\mathbf{A}_{22}\right)^{-1}\left[\mathbf{A}_{21}+\mathbf{B}_{2} \mathbf{F}-\overline{\mathbf{H}}\left(\mathbf{A}_{11}+\mathbf{B}_{1} \mathbf{F}\right)\right] .
$$

Equation (25) describes the T-map, $T(\overline{\mathbf{H}})$, from $\overline{\mathbf{H}}$ to $\mathbf{H}$; it is, of course, equivalent to equation (20).

Lemma 2 A symmetric Markov-perfect Stackelberg-Nash equilibrium is locally IE-stable under private sector learning if and only if all eigenvalues of

$$
-\left[\mathbf{I} \otimes\left(\mathbf{H} \mathbf{A}_{12}-\mathbf{A}_{22}\right)\right]^{-1}\left[\left(\mathbf{A}_{11}+\mathbf{A}_{12} \mathbf{H}+\mathbf{B}_{1} \mathbf{F}\right)^{\prime} \otimes \mathbf{I}\right]
$$

have modulus less than 1.

Proof. Applying standard matrix calculus rules to equation (25), the total differential can be written as

$$
\left(\mathbf{H A}_{12}-\mathbf{A}_{22}\right) d(\mathbf{H})+d(\overline{\mathbf{H}}) \mathbf{A}_{12} \mathbf{H}+d(\overline{\mathbf{H}})\left(\mathbf{A}_{11}+\mathbf{B}_{1} \mathbf{F}\right)=\mathbf{0}
$$

which after vectorizing can be rearranged to give

$$
v e c[d(\mathbf{H})]=-\left[\mathbf{I} \otimes\left(\mathbf{H} \mathbf{A}_{12}-\mathbf{A}_{22}\right)\right]^{-1}\left[\left(\mathbf{A}_{11}+\mathbf{A}_{12} \mathbf{H}+\mathbf{B}_{1} \mathbf{F}\right)^{\prime} \otimes \mathbf{I}\right] v e c[d(\overline{\mathbf{H}})] .
$$

We apply Lemma 1 to obtain the required result. Note that invertability of $\left(\mathbf{H A}_{12}-\mathbf{A}_{22}\right)$ is virtually ensured by the assumption that $\mathbf{A}_{22}$ has full rank. 
Because the eigenvalues of $\mathbf{M}=\mathbf{A}_{11}+\mathbf{A}_{12} \mathbf{H}+\mathbf{B}_{1} \mathbf{F}$ are all strictly less than $\beta^{-\frac{1}{2}}$, equilibria that are not locally IE-stable under private sector learning are those for which $\left(\mathbf{H} \mathbf{A}_{12}-\mathbf{A}_{22}\right)$ is close to equaling the null matrix.

In addition, there is an important connection between implementability of an equilibrium and whether an equilibrium is IE-stable under private sector learning.

Lemma 3 If a symmetric Markov-perfect Stackelberg-Nash equilibrium is implementable, then it is locally IE-stable under private sector learning.

Proof. See McCallum (2007).

\subsubsection{Eductive learning by the leader}

We now turn to the case where the policymaker is learning, but private agents are not. Here we examine whether the policymaker can learn $\{\mathbf{F}, \mathbf{V}\}$, given $\{\mathbf{H}\}$. We show that although learning by policymakers is interesting and important in many contexts, here this local IEstability criterion cannot discriminate among equilibria.

For a given private sector decision rule, $\mathbf{y}_{t}=\mathbf{H x}_{t}$, and a postulated policy rule

$$
\mathbf{u}_{t}=\overline{\mathbf{F}} \mathbf{x}_{t}
$$

and a postulated value function matrix $\overline{\mathbf{V}}$, the T-map $T(\overline{\mathbf{F}}, \overline{\mathbf{V}})$, from $\{\overline{\mathbf{F}}, \overline{\mathbf{V}}\}$ to $\{\mathbf{F}, \mathbf{V}\}$ is described by the following updating relationships

$$
\begin{aligned}
& \mathbf{F}=-\left(\widehat{\mathbf{Q}}+\beta \widehat{\mathbf{B}}^{\prime} \overline{\mathbf{V}} \widehat{\mathbf{B}}\right)^{-1}\left(\widehat{\mathbf{U}}^{\prime}+\beta \widehat{\mathbf{B}}^{\prime} \overline{\mathbf{V}} \widehat{\mathbf{A}}\right) \\
& \mathbf{V}=\widehat{\mathbf{W}}+2 \widehat{\mathbf{U}} \mathbf{F}+\mathbf{F}^{\prime} \widehat{\mathbf{Q}} \mathbf{F}+\beta(\widehat{\mathbf{A}}+\widehat{\mathbf{B}} \mathbf{F})^{\prime} \overline{\mathbf{V}}(\widehat{\mathbf{A}}+\widehat{\mathbf{B}} \mathbf{F}),
\end{aligned}
$$

where $\widehat{\mathbf{W}}, \widehat{\mathbf{U}}, \widehat{\mathbf{Q}}, \widehat{\mathbf{A}}$, and $\widehat{\mathbf{B}}$ are defined by equations (14)-(18) and do not depend on $\mathbf{F}$ or $\mathbf{V}$ ( or on $\overline{\mathbf{F}}$ or $\overline{\mathbf{V}}$ ). Notice, that $\mathbf{F}$, given $\mathbf{H}$, is uniquely determined by $\mathbf{V}$, so the key to learning $\mathbf{F}$ is to learn $\mathbf{V}$. As a consequence, without loss of generality we can substitute equation (26) into equation (27) and analyze the the learning problem using the concentrated T-map $T(\overline{\mathbf{V}})=\mathbf{V}$.

Lemma 4 All symmetric Markov-perfect Stackelberg-Nash equilibria are locally IE-stable under policymaker learning. 
Proof. Applying standard matrix calculus rules to equations (26) and (27), total differentials are given by

$$
\begin{aligned}
\left(\widehat{\mathbf{Q}}+\beta \widehat{\mathbf{B}}^{\prime} \mathbf{V} \widehat{\mathbf{B}}\right) d(\mathbf{F})+\beta \widehat{\mathbf{B}}^{\prime} d(\overline{\mathbf{V}})(\widehat{\mathbf{A}}+\widehat{\mathbf{B}} \mathbf{F}) & =\mathbf{0} \\
2\left[\widehat{\mathbf{U}}+\mathbf{F}^{\prime} \widehat{\mathbf{Q}}+\beta(\widehat{\mathbf{A}}+\widehat{\mathbf{B}} \mathbf{F})^{\prime} \mathbf{V} \widehat{\mathbf{B}}\right] d(\mathbf{F})+\beta(\widehat{\mathbf{A}}+\widehat{\mathbf{B}} \mathbf{F})^{\prime} d(\overline{\mathbf{V}})(\widehat{\mathbf{A}}+\widehat{\mathbf{B}} \mathbf{F}) & =\mathbf{I} d(\mathbf{V})
\end{aligned}
$$

Using equation (28) to solve for $d(\mathbf{F})$ and substituting the resulting expression into equation (29) yields, upon rearranging,

$\beta\left[-2\left(\widehat{\mathbf{U}}+\beta \widehat{\mathbf{A}}^{\prime} \mathbf{V B}\right)\left(\widehat{\mathbf{Q}}+\beta \widehat{\mathbf{B}}^{\prime} \mathbf{V} \widehat{\mathbf{B}}\right)^{-1} \widehat{\mathbf{B}}^{\prime}-2 \mathbf{F}^{\prime} \widehat{\mathbf{B}}^{\prime}+(\widehat{\mathbf{A}}+\widehat{\mathbf{B}} \mathbf{F})^{\prime}\right] d(\overline{\mathbf{V}})(\widehat{\mathbf{A}}+\widehat{\mathbf{B}} \mathbf{F})=\mathbf{I} d(\mathbf{V})$,

which, given equation (26), collapses to

$$
\beta(\widehat{\mathbf{A}}+\widehat{\mathbf{B}} \mathbf{F})^{\prime} d(\overline{\mathbf{V}})(\widehat{\mathbf{A}}+\widehat{\mathbf{B}} \mathbf{F})=\mathbf{I} d(\mathbf{V}) .
$$

After vectorizing and recognizing that $\mathbf{M}=\widehat{\mathbf{A}}+\widehat{\mathbf{B F}}$, equation (30) can be written as

$$
\operatorname{vec}[d(\mathbf{V})]=\beta\left(\mathbf{M}^{\prime} \otimes \mathbf{M}^{\prime}\right) \operatorname{vec}[d(\overline{\mathbf{V}})] .
$$

The matrix $\beta\left(\mathbf{M}^{\prime} \otimes \mathbf{M}^{\prime}\right)$ defines the derivative map $D T(\mathbf{V})$. Applying Lemma 1, a symmetric Markov-perfect Stackelberg-Nash equilibria $\{\mathbf{H}, \mathbf{F}, \mathbf{M}, \mathbf{V}, d\}$ is a local IE-stable policy equilibrium if and only if all of the eigenvalues of $D T(\mathbf{V})$ have modulus less than 1 . Because the eigenvalues of $\mathbf{M}$ all have modulus less than $\beta^{-\frac{1}{2}}$ in all symmetric Markov-perfect Stackelberg-Nash equilibria the result follows.

\subsubsection{Joint eductive learning}

Finally, we analyze the case in which both private agents and the policymaker are learning. The postulated policy and decision rules are

$$
\begin{aligned}
& \mathbf{y}_{t}=\overline{\mathbf{H}} \mathbf{x}_{t} \\
& \mathbf{u}_{t}=\overline{\mathbf{F}} \mathbf{x}_{t}
\end{aligned}
$$

and the postulated value function matrix is $\overline{\mathbf{V}}$. Then the actual policy and decision rules are given by

$$
\begin{aligned}
\mathbf{H} & =\mathbf{J}+\mathbf{K} \mathbf{F} \\
\mathbf{F} & =-\left(\widehat{\mathbf{Q}}+\beta \widehat{\mathbf{B}}^{\prime} \overline{\mathbf{V}} \widehat{\mathbf{B}}\right)^{-1}\left(\widehat{\mathbf{U}}+\beta \widehat{\mathbf{B}}^{\prime} \overline{\mathbf{V}} \widehat{\mathbf{A}}\right) \\
\mathbf{V} & =\widehat{\mathbf{W}}+2 \widehat{\mathbf{U}} \mathbf{F}+\mathbf{F}^{\prime} \widehat{\mathbf{Q}} \mathbf{F}+\beta(\widehat{\mathbf{A}}+\widehat{\mathbf{B}} \mathbf{F})^{\prime} \overline{\mathbf{V}}(\widehat{\mathbf{A}}+\widehat{\mathbf{B}} \mathbf{F})
\end{aligned}
$$


where

$$
\begin{aligned}
\mathbf{J} & =\left(\mathbf{A}_{22}-\overline{\mathbf{H}} \mathbf{A}_{12}\right)^{-1}\left(\overline{\mathbf{H}} \mathbf{A}_{11}-\mathbf{A}_{21}\right), \\
\mathbf{K} & =\left(\mathbf{A}_{22}-\overline{\mathbf{H}} \mathbf{A}_{12}\right)^{-1}\left(\overline{\mathbf{H}} \mathbf{B}_{1}-\mathbf{B}_{2}\right)
\end{aligned}
$$

and $\widehat{\mathbf{W}}, \widehat{\mathbf{U}}, \widehat{\mathbf{Q}}, \widehat{\mathbf{A}}$, and $\widehat{\mathbf{B}}$ are defined by equations (14)-(18) and are functions of $\mathbf{J}$ and $\mathbf{K}$.

Given equations (34) and (35), equations (31)-(33) describe the T-map, $T(\overline{\mathbf{H}}, \overline{\mathbf{F}}, \overline{\mathbf{V}})$, from $\{\overline{\mathbf{H}}, \overline{\mathbf{F}}, \overline{\mathbf{V}}\}$, to $\{\mathbf{H}, \mathbf{F}, \mathbf{V}\}$.

Lemma 5 A symmetric Markov-perfect Stackelberg-Nash equilibrium is locally IE-stable under joint learning if and only if all eigenvalues of the matrix $\mathbf{P}^{-1} \mathbf{L}$ in

$$
\operatorname{vec}[d(\mathbf{G})]=\mathbf{P}^{-1} \mathbf{L} v e c[d(\overline{\mathbf{G}})],
$$

where vec $[d(\mathbf{G})]=\left[\operatorname{vec}[d(\mathbf{H})]^{\prime} \quad \operatorname{vec}[d(\mathbf{F})]^{\prime} \quad \operatorname{vec}[d(\mathbf{V})]^{\prime}\right]^{\prime}$ and $\mathbf{P}$ and $\mathbf{L}$ are characterized below, have modulus less than 1.

Proof. Total differentials of equations (31)-(35) about the point $\{\mathbf{H}, \mathbf{F}, \mathbf{V}, \mathbf{J}, \mathbf{K}\}$ are given by

$$
\begin{aligned}
\mathbf{0}= & d(\mathbf{J})+d(\mathbf{K}) \mathbf{F}+\mathbf{K} d(\mathbf{F})-d(\mathbf{H}) \\
\mathbf{0}= & d(\overline{\mathbf{H}}) \widehat{\mathbf{A}}-\left(\mathbf{A}_{22}-\mathbf{H} \mathbf{A}_{12}\right) d(\mathbf{J}), \\
\mathbf{0}= & d(\overline{\mathbf{H}}) \widehat{\mathbf{B}}-\left(\mathbf{A}_{22}-\mathbf{H} \mathbf{A}_{12}\right) d(\mathbf{K}), \\
\mathbf{0}= & \beta \widehat{\mathbf{B}}^{\prime} d(\overline{\mathbf{V}}) \mathbf{M}+\left(\widehat{\mathbf{Q}}+\beta \widehat{\mathbf{B}}^{\prime} \mathbf{V} \widehat{\mathbf{B}}\right) d(\mathbf{F})+2\left(\mathbf{K}^{\prime} \mathbf{W}_{22}+\mathbf{U}_{2}^{\prime}+\beta \widehat{\mathbf{B}}^{\prime} \mathbf{V A} \mathbf{A}_{12}\right) d(\mathbf{K}) \mathbf{F} \\
& +\left(\mathbf{W}_{12}+\mathbf{J}^{\prime} \mathbf{W}_{22}+\beta \widehat{\mathbf{A}}^{\prime} \mathbf{V} \mathbf{A}_{12}\right) d(\mathbf{K})+\left(\mathbf{K}^{\prime} \mathbf{W}_{22}+\mathbf{U}_{2}^{\prime}+\beta \widehat{\mathbf{B}}^{\prime} \mathbf{V} \mathbf{A}_{12}\right) d(\mathbf{J}), \\
\mathbf{0}= & 2\left(\widehat{\mathbf{U}}+\mathbf{F}^{\prime} \widehat{\mathbf{Q}}+\beta \mathbf{M}^{\prime} \mathbf{V} \widehat{\mathbf{B}}\right) d(\mathbf{F})+2\left(\mathbf{W}_{12}+\mathbf{H}^{\prime} \mathbf{W}_{22}+\mathbf{F}^{\prime} \mathbf{U}_{2}^{\prime}+\beta \mathbf{M}^{\prime} \mathbf{V} \mathbf{A}_{12}\right) d(\mathbf{J}) \\
& +2\left(\mathbf{W}_{12}+\mathbf{H}^{\prime} \mathbf{W}_{22}+\mathbf{F}^{\prime} \mathbf{U}_{2}^{\prime}+\beta \mathbf{M}^{\prime} \mathbf{V} \mathbf{A}_{12}\right) d(\mathbf{K}) \mathbf{F}+\beta \mathbf{M}^{\prime} d(\overline{\mathbf{V}}) \mathbf{M}-d(\mathbf{V}) .
\end{aligned}
$$

Now, using equations (37) and (38) to solve for $d(\mathbf{J})$ and $d(\mathbf{K})$, respectively, and substituting 
these expressions into equations (36), (39), and (40) produces

$$
\begin{aligned}
\mathbf{0}= & \mathbf{K} d(\mathbf{F})+\left(\mathbf{A}_{22}-\mathbf{H} \mathbf{A}_{12}\right)^{-1} d(\overline{\mathbf{H}}) \mathbf{M}-d(\mathbf{H}) \\
\mathbf{0}= & \beta \widehat{\mathbf{B}}^{\prime} d(\overline{\mathbf{V}}) \mathbf{M}+\left(\widehat{\mathbf{Q}}+\beta \widehat{\mathbf{B}}^{\prime} \mathbf{V} \widehat{\mathbf{B}}\right) d(\mathbf{F}) \\
& +\left(\mathbf{W}_{12}+\mathbf{J}^{\prime} \mathbf{W}_{22}+\beta \widehat{\mathbf{A}}^{\prime} \mathbf{V} \mathbf{A}_{12}\right)\left(\mathbf{A}_{22}-\mathbf{H} \mathbf{A}_{12}\right)^{-1} d(\overline{\mathbf{H}}) \widehat{\mathbf{B}} \\
& +2\left(\mathbf{K}^{\prime} \mathbf{W}_{22}+\mathbf{U}_{2}^{\prime}+\beta \widehat{\mathbf{B}}^{\prime} \mathbf{V} \mathbf{A}_{12}\right)\left(\mathbf{A}_{22}-\mathbf{H} \mathbf{A}_{12}\right)^{-1} d(\overline{\mathbf{H}}) \widehat{\mathbf{B}} \mathbf{F} \\
& +\left(\mathbf{K}^{\prime} \mathbf{W}_{22}+\mathbf{U}_{2}^{\prime}+\beta \widehat{\mathbf{B}}^{\prime} \mathbf{V} \mathbf{A}_{12}\right)\left(\mathbf{A}_{22}-\mathbf{H} \mathbf{A}_{12}\right)^{-1} d(\overline{\mathbf{H}}) \widehat{\mathbf{A}} \\
\mathbf{0}= & 2\left(\widehat{\mathbf{U}}+\mathbf{F}^{\prime} \widehat{\mathbf{Q}}+\beta \mathbf{M}^{\prime} \mathbf{V} \widehat{\mathbf{B}}\right) d(\mathbf{F})+\beta \mathbf{M}^{\prime} d(\overline{\mathbf{V}}) \mathbf{M}-d(\mathbf{V}) \\
& +2\left(\mathbf{W}_{12}+\mathbf{H}^{\prime} \mathbf{W}_{22}+\mathbf{F}^{\prime} \mathbf{U}_{2}^{\prime}+\beta \mathbf{M}^{\prime} \mathbf{V} \mathbf{A}_{12}\right)\left(\mathbf{A}_{22}-\mathbf{H} \mathbf{A}_{12}\right)^{-1} d(\overline{\mathbf{H}}) \mathbf{M},
\end{aligned}
$$

where, again, the invertability of $\left(\mathbf{A}_{22}-\mathbf{H} \mathbf{A}_{12}\right)$ is virtually ensured by the assumption that $\mathbf{A}_{22}$ has full rank. By vectorizing and stacking equations (41) - (43) they can be written in the form

$$
\mathbf{P} v e c[d(\mathbf{G})]=\mathbf{L} v e c[d(\overline{\mathbf{G}})]
$$

where

$$
\mathbf{P}=\left[\begin{array}{ccc}
\mathbf{I} & -\mathbf{K} & \mathbf{0} \\
\mathbf{0} & -\left(\widehat{\mathbf{Q}}+\beta \widehat{\mathbf{B}}^{\prime} \mathbf{V} \widehat{\mathbf{B}}\right) & \mathbf{0} \\
\mathbf{0} & -2\left(\widehat{\mathbf{U}}+\mathbf{F}^{\prime} \widehat{\mathbf{Q}}+\beta \mathbf{M}^{\prime} \mathbf{V} \widehat{\mathbf{B}}\right) & \mathbf{I}
\end{array}\right]
$$

and $\mathbf{L}$ is defined implicitly by equations (41)-(43). Because $\left(\widehat{\mathbf{Q}}+\beta \widehat{\mathbf{B}}^{\prime} \mathbf{V} \widehat{\mathbf{B}}\right)$ has full rank in any symmetric Markov-perfect Stackelberg-Nash equilibrium, $\mathbf{P}$ too has full rank. The result follows.

Lemma 6 The equilibrium identified by Oudiz and Sachs (1985) and all equilibria identified by Backus and Driffill (1986) are IE-stable under joint learning.

Proof. The iterative numerical schemes employed by the Backus and Driffill (1986) and Oudiz and Sachs (1985) solution methods coincide with the learning scheme described by the T-map (31) - (33). As a consequence, these numerical solution methods apply direct numerical iterations on the non-linear T-map. If these numerical solution methods converge to a fix-point, then, by construction, the resulting equilibrium is IE-stable under joint learning.

Before leaving this section, we wish to emphasize that the IE-stability criteria associated with private sector learning and joint learning, although connected, are distinct. Joint learn- 
ability of an equilibrium neither implies nor is implied by private sector learnability of that equilibrium.

\subsection{Self-enforceability}

We now approach the coordination problem by asking whether an equilibrium is self-enforceable (Bernheim, Peleg, and Whinston, 1987; Bernheim and Whinston, 1987), robust to the potential formation of non-cooperative coalitions. Intuitively, policymakers can more easily coordinate on an equilibrium if that equilibrium is self-enforceable, and no group of policymakers finds it beneficial to form a coalition and deviate from equilibrium play. Assume that the model has $N$ symmetric Markov-perfect Stackelberg-Nash equilibria. Because the economic environment is one in which there is complete and perfect information, the existence and nature of all $N$ equilibria is known to all agents. Moreover, the $N$ equilibria can (invariably) be welfare ranked and, as a consequence, agents are not indifferent to which equilibrium prevails.

Treating the policy rules associated with the $N$ equilibria as a set of policy actions, because the equilibria are Nash, if policymakers in periods $s=t+1, \ldots, \infty$ are expected to play $\overline{\mathbf{F}}_{j}$, $j=1, \ldots, N$, then the period- $t$ policymaker's best response is to also play $\mathbf{F}_{j}$. However, although it is never beneficial for the period- $t$ policymaker to unilaterally deviate from Nash play, the period- $t$ policymaker can potentially benefit from deviations that involve multiple policymakers. With this in mind, we introduce the possibility that a "small" coalition of policymakers could form that may deviate from the play prescribed in equilibrium $j$. The coalitions that we envisage are motivated by the fact that policymakers have tenures spanning multiple decision periods and, as a consequence, we model them in terms of sequential players. ${ }^{6}$

Let $\left(p_{j}+1\right)$ represent the number of sequential players in a potential coalition and consider the period- $t$ policymaker's best response where the predicted future play is given by $\left\{\mathbf{F}_{i}^{t+1}, \ldots, \mathbf{F}_{i}^{t+p_{j}}, \mathbf{F}_{j}^{t+p_{j}+1}, \mathbf{F}_{j}^{t+p_{j}+2}, \ldots\right\}, j \neq i$, with private agents in periods $s=t, \ldots, \infty$ responding according to their reaction function. In this scenario, during periods $s=t+p_{j}+$ $1, \ldots, \infty$ the policy rule and private-sector decision rules are given by $\mathbf{F}_{j}$ and $\mathbf{H}_{j}$, respectively. However, during periods $s=t, \ldots, t+p_{j}$ the policy rule is given by $\mathbf{F}_{i}$ and private agents respond according to their reaction function,

$$
\mathbf{H}^{s}=\left(\mathbf{H}^{s+1} \mathbf{A}_{12}-\mathbf{A}_{22}\right)^{-1}\left[\mathbf{A}_{21}+\mathbf{B}_{2} \mathbf{F}_{i}-\mathbf{H}^{s+1}\left(\mathbf{A}_{11}+\mathbf{B}_{1} \mathbf{F}_{i}\right)\right] .
$$

\footnotetext{
${ }^{6}$ One might view the group of deviating policymakers to be small if it numbers less than a policymaker's average tenure. In the U. S., Federal Reserve chairmen are appointed to a four year term, but the average tenure is somewhat longer. In the U. K., monetary policy committee members have three-year contracts that overlap to prevent members from retiring simultaneously.
} 
Given equation (44), the law-of-motion for the state vector during periods $s=t, \ldots, t+p_{j}$ is

$$
\mathbf{M}^{s}=\mathbf{A}_{11}+\mathbf{A}_{12} \mathbf{H}^{s}+\mathbf{B}_{1} \mathbf{F}_{i} .
$$

We know that if $p_{j}=0$, then the period- $t$ policymaker's best response is to play $\mathbf{F}_{j}$. However, as $p_{j}$ increases, the period- $t$ policymaker's best response can switch from $\mathbf{F}_{j}$ to $\mathbf{F}_{i}$. For each $\mathbf{F}_{j}$, we calculate the number of periods of multilateral deviation $p_{j}$ required to switch the period- $t$ policymaker's best response from $\mathbf{F}_{j}$ to $\mathbf{F}_{i}$. Of course, although the period- $t$ policymaker's best response may switch from $\mathbf{F}_{j}$ to $\mathbf{F}_{i}$ as $p_{j}$ increases, it need not. In fact, whether the period- $t$ policymaker's best response switches from $\mathbf{F}_{j}$ to $\mathbf{F}_{i}$ as $p_{j}$ increases turns on whether equilibrium $i$ is Pareto-preferred to equilibrium $j$ and on whether equilibrium $i$ is locally IE-stable under private sector learning.

Lemma 7 The period-t policymakers best response will switch from $\mathbf{F}_{j}$ to $\mathbf{F}_{i}$ in the limit as $p_{j} \uparrow \infty$ if and only if equilibrium $i$ is Pareto-preferred to equilibrium $j$ and equilibrium $i$ is locally IE-stable under private sector learning.

Proof. Consider equation (44). If equilibrium $i$ is locally IE-stable under private sector learning, then, $\mathbf{H}^{s} \rightarrow \mathbf{H}^{i}$ in the limit as $p_{j} \uparrow \infty$, which implies $\mathbf{M}^{s} \rightarrow \mathbf{M}^{i}$ and $\mathbf{V}^{s} \rightarrow \mathbf{V}^{i}$. Because equilibrium $i$ Pareto-dominates equilibrium $j$, the period- $t$ policymaker's best response must switch from $\mathbf{F}_{j}$ to $\mathbf{F}_{i}$. On the contrary, if equilibrium $i$ is not locally IE-stable under private sector learning, then although $\mathbf{H}^{s}$ may converge to $\widetilde{\mathbf{H}} \neq \mathbf{H}^{i}$ in the limit as $p_{j} \uparrow \infty$, because $\widetilde{\mathbf{H}} \neq \mathbf{H}^{i}$ the period- $t$ policymaker's best response cannot be $\mathbf{F}_{i}$.

An additional issue that we consider is whether coalition forming can generate a switch from the prevailing equilibrium to the Pareto-preferred equilibrium and, if so, how large of a coalition is required to generate such a switch. It follows from Lemma 6 that the Paretopreferred equilibrium must be locally IE-stable under private sector learning if such a switch is to occur.

\subsection{Properness}

To analyze whether an equilibrium is proper in the spirit of Myerson (1978), we consider a particular perturbation of the model and ask whether the equilibrium under consideration is a solution to the perturbed model in the limit as the perturbation tends to zero. The particular perturbation that we consider is to the information set that private agents use to form expectations. Thus, we recast equation (2) as

$$
(1-\epsilon) \mathrm{E}_{t} \mathbf{y}_{t+1}+\epsilon \mathrm{E}_{t-1} \mathbf{y}_{t+1}=\mathbf{A}_{21} \mathbf{x}_{t}+\mathbf{A}_{22} \mathbf{y}_{t}+\mathbf{B}_{2} \mathbf{u}_{t},
$$


where $\epsilon \in[0,1]$ represents the perturbation. When $\epsilon=1$, private agents form expectations using period $t-1$ information while when $\epsilon=0$ (and the model is unperturbed), private agents form expectations using period $t$ information. With the policy objective function continuing to be given by equation (3), the $\epsilon$-perturbed model is given by equations (1) and (45).

For this particular form of perturbation, equilibrium $j, j=1, \ldots, N$, is considered $\epsilon$-proper if in the limit as $\epsilon \downarrow 0$ equilibrium $j$ is a symmetric Markov-perfect Stackelberg-Nash equilibrium in the $\epsilon$-perturbed model.

\section{Applications}

In this section we analyze two New Keynesian models that exhibit multiple symmetric Markovperfect Stackelberg-Nash equilibria. The first is a version of the sticky price model with government debt developed by Leeper (1991). The second is a sticky price New Keynesian model in the spirit of Woodford (2003, Chapter 5) and Sveen and Weinke (2007), but with partial inflation indexation. This second model is especially notable because it resides at the core of many New Keynesian models, such as those developed by Christiano, Eichenbaum, and Evans (2005) and Smets and Wouters (2007)

\subsection{A DSGE model with government debt}

The economy is populated by a representative household, by a unit-continuum of monopolistically competitive firms, and by a single large government that conducts separately monetary policy and fiscal policy. Fiscal policy is conducted via a mechanistic rule that relates government spending, $g_{t}$, inversely to the stock of real government debt, $b_{t}$. Monetary policy, in contrast, is conducted by choosing a setting for the nominal interest rate on a one-period nominal bond, $r_{t}$, optimally, but under discretion. Importantly, when formulating monetary policy the central bank takes the fiscal rule into account. Monopolistically competitive firms produce according to a production function that depends only on labor and these goods are combined via a Dixit and Stiglitz (1977) technology to produce aggregate output, $y_{t}$, which is allocated to either private consumption, $c_{t}$, or government spending. Households choose their consumption and leisure, $1-l_{t}$, and can transfer income through time through their holdings of government bonds. The government issues debt period-by-period in order to pay the principle and interest on its existing debt and to fund any discrepancy between its spending and its tax revenues, $\tau y_{t}$, where $\tau \in(0,1)$ is the tax rate on income. Firms set prices subject to a Calvo (1983) nominal price rigidity and aggregation across prices leads to a New Keynesian 
Phillips curve relating inflation, $\pi_{t}$, to the expected future inflation, real marginal costs, and a serially correlated markup shock, $v_{t}$.

When log-linearized about a zero-inflation nonstochastic steady state the equations that constrain the monetary policy decision problem can be written as

$$
\begin{aligned}
\pi_{t} & =\beta \mathrm{E}_{t} \pi_{t+1}+\frac{(1-\gamma \beta)(1-\gamma)}{\sigma \gamma(\varepsilon+\psi)}\left(\psi c_{t}+\sigma y_{t}\right)+v_{t}, \\
c_{t} & =\mathrm{E}_{t} c_{t+1}-\sigma\left(r_{t}-\mathrm{E}_{t} \pi_{t+1}\right), \\
y_{t} & =(1-\theta) g_{t}+\theta c_{t}, \\
b_{t+1} & =\chi r_{t}+\frac{1}{\beta}\left(b_{t}-\chi \pi_{t}+(1-\theta) g_{t}-\tau y_{t}\right), \\
g_{t} & =-\lambda b_{t},
\end{aligned}
$$

with the monetary policy objective function, a second-order accurate approximation ${ }^{7}$ to household utility, taking the form (Blake and Kirsanova, 2007)

$$
L_{t}=(1-\beta) \mathrm{E}_{t} \sum_{k=t}^{\infty} \beta^{(k-t)}\left[\pi_{k}^{2}+\frac{\psi(1-\gamma \beta)(1-\gamma)}{(\epsilon+\psi) \gamma \epsilon}\left(\frac{1}{\psi} y_{k}^{2}+\frac{\theta}{\sigma} c_{k}^{2}+\frac{(1-\theta)}{\sigma} g_{k}^{2}\right)\right] .
$$

The parameter $\lambda$, which reflects the response of government spending to real debt, plays a crucial role in the analysis. If the fiscal response parameter is "relatively large" then fiscal policy bears the burden of stabilizing the stock of debt and there is a unique symmetric Markovperfect Stackelberg-Nash equilibrium. In this equilibrium, following an adverse markup shock, fiscal policy returns the real government debt quickly to its steady state level while monetary policy stabilizes inflation and output by raising the nominal interest rate in order to lower real marginal costs. If the fiscal control is "relatively small", then again there is a unique equilibrium in which monetary policy bears the burden of stabilizing the stock of debt. In the spirit of Leeper (1991), the former case can be thought of as one it which fiscal policy is passive and monetary policy is active and the latter case as one in which fiscal policy is active and monetary policy is passive. For an "intermediate" strength of fiscal control, however, we find three equilibria. ${ }^{8}$

In Table 1, we report the policy rule, $\mathbf{F}$, and the private-sector decision rules, $\mathbf{H}$, for all three equilibria.

\footnotetext{
${ }^{7}$ When deriving this approximation, Blake and Kirsanova (2007) assume the presence of an efficient production/employment subsidy, funded by a lump-sum tax, that offsets the output distortion caused by monopolistic competition.

${ }^{8}$ We parameterize the model as follows. We set the discount factor, $\beta$, to 0.99 , the elasticity of intertemporal substitution, $\sigma$, to 0.5 , the consumption-output ratio, $\theta$, to 0.75 , the steady-state debt-to-output ratio, $\chi$, to 0.1 , the elasticity of substitution between goods, $\varepsilon$, to 11 , the Calvo price-rigidity, $\gamma$, to 0.75 , the labor supply elasticity, $\psi$, to 2 , the income tax rate, $\tau$, to $(1-\beta) \chi+(1-\theta)$ and the fiscal policy parameter, $\lambda$, to 1.1 . We set the $\operatorname{AR}(1)$ coefficient in the markup shock process to 0.3 .
} 


\begin{tabular}{c|c|c}
\hline \hline \multicolumn{4}{|c}{ Table 1: Policy rules in equilibrium } \\
\hline \multirow{2}{*}{ Eqm } & $\mathbf{F}=\left[\begin{array}{ll}F_{v} & F_{b}\end{array}\right]$ & $\mathbf{H}=\left[\begin{array}{ll}H_{c v} & H_{c b} \\
H_{\pi v} & H_{\pi b}\end{array}\right]$ \\
\hline $\mathrm{A}$ & {$\left[\begin{array}{ll}-5.1657 & -0.8476\end{array}\right]$} & {$\left[\begin{array}{cc}2.4392 & 0.9401 \\
1.4385 & 0.0585\end{array}\right]$} \\
\hline $\mathrm{B}$ & {$\left[\begin{array}{ll}7.7386 & -0.2414\end{array}\right]$} & {$\left[\begin{array}{cc}-4.3044 & 0.4334 \\
1.3073 & 0.0374\end{array}\right]$} \\
\hline $\mathrm{C}$ & {$\left[\begin{array}{ll}13.5114 & -0.1066\end{array}\right]$} & {$\left[\begin{array}{cc}-8.3962 & 0.2392 \\
1.1339 & 0.0216\end{array}\right]$} \\
\hline \hline
\end{tabular}

The three policy rules presented in Table 1 are qualitatively and quantitatively quite different. Specifically, monetary policy can be thought of as being passive in equilibrium A and active in equilibria B and C. ${ }^{9}$ Thus, characterizing equilibrium A as "passive", equilibrium B as "moderately active", and equilibrium C as "active", Table 1 reveals a trade-off between the response to government debt and the response to the markup shock: the more active the policy the more aggressively interest rates are raised in response to the markup shock.

To understand why multiple equilibria arise in this model, recognize that following a markup shock the challenge facing the central bank is to bring inflation down without creating too large of a recession. According to the Phillips curve, in any stationary equilibrium inflation depends on the entire expected future path of real marginal costs,

$$
\pi_{t}=\mathrm{E}_{t} \sum_{k=t}^{\infty} \beta^{(k-t)}\left[\frac{(1-\gamma \beta)(1-\gamma)}{\sigma \gamma(\varepsilon+\psi)} m c_{k}+v_{k}\right]
$$

where real marginal costs are given by

$$
m c_{t}=\psi c_{t}+\sigma y_{t}
$$

Notice that when the discount factor, $\beta$, is large $m c_{t}$ and $m c_{t+1}$ are highly substitutable in terms of their effect on period-t inflation. Clearly, if inflation is above target, then there are multiple paths for real marginal costs that will return inflation to target. Each of these paths for real marginal costs is associated with a different monetary policy and each has a

\footnotetext{
${ }^{9}$ To this point, consider the monetary policy rule in equilibrium A. It is useful to express this policy rule as a relationship whereby the nominal interest rate responds to inflation and real debt. When written in this form the policy rule is

$$
r_{t}=-3.59103 \pi_{t}-0.637409 b_{t} .
$$

In contrast, the policy rule in equilibrium $\mathrm{C}$ is

$$
r_{t}=11.9156 \pi_{t}-0.363488 b_{t} .
$$

In the spirit of Leeper (1991), the policy rule in equilibrium A can be thought of as being passive because it suggests that the interest rate be lowered in response to a rise in inflation.
} 
different cost in terms of loss. The policymaker might choose a policy that involves lower future real marginal costs if that policy allows the costs of bringing inflation back to target to be deferred, even if that policy means tolerating slightly higher inflation today.

Consider the case where future policymakers are expected to employ a policy rule that responds only weakly to $b_{t}$. In this case a monetary policy that seeks to counter the markup shock by raising the real interest rate will be attractive. The higher real interest rate induces households to defer consumption, which, from equation (46), achieves the goal of lowering real marginal costs today and placing downward pressure on inflation. Of course, the higher interest rate also raises the cost of financing the government debt, which together with the fact that the decline in consumption lowers output and government tax revenues, leads to a rise in $b_{t}$. Where the success of this policy would be undone if future policymakers were to cut interest rates aggressively in response to the rise in $b_{t}$, because this would cause future real marginal costs to rise, it is sustained on the expectation that future policymakers will not attempt to solve the fiscal deficit problem by stimulating the economy. This line of reasoning gives rise to equilibrium $\mathrm{C}$ (or $\mathrm{B}$ ).

In contrast, if future policymakers are expected to tighten monetary policy aggressively in response to a decline in government debt, then a monetary policy that stimulates the economy today can achieve lower inflation over time, even if it permits higher inflation today, provided real marginal costs decline in the future. By lowering the interest rate in response to the markup shock, monetary policy stimulates the economy and causes real marginal costs to rise, which is inflationary. However, because this policy raises government tax receipts and lowers the cost of financing debt, it causes the stock of government debt to decline. Since future policymakers are expected to tighten monetary policy aggressively in response to a decline in government debt, this policy achieves lower inflation over time because it induces tighter policy in the future. This line of reasoning gives rise to equilibrium A. 

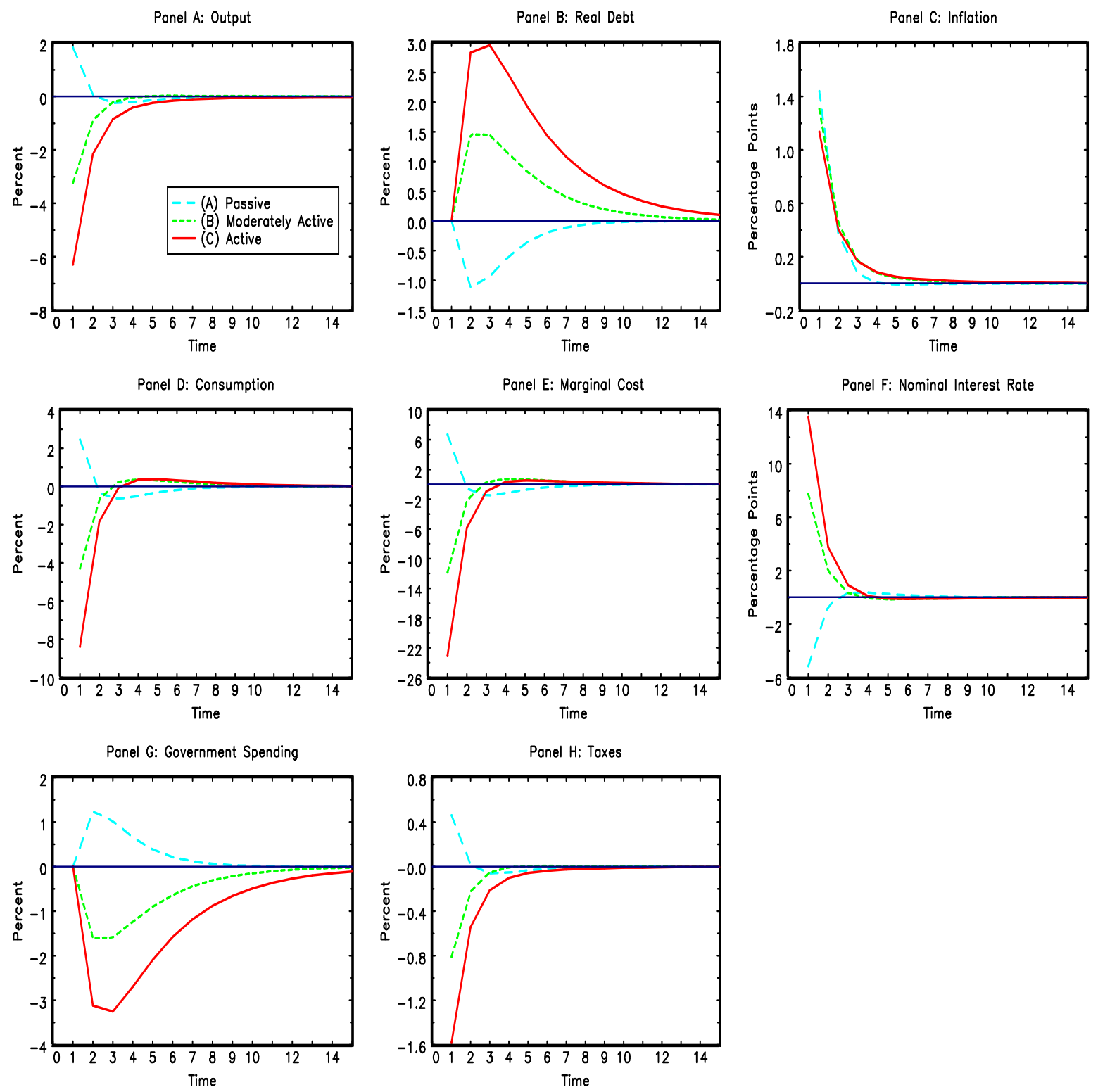

Figure 1: Responses to unit markup shock

The economy's behavior in each equilibria can be seen in Figure 1, which shows the responses of key variables to a unit markup shock. Focusing first on the active and moderately active equilibria (equilibria $\mathrm{C}$ and $\mathrm{B}$, respectively), inflation rises following the markup shock (panel C) and the policy response is to raise the nominal interest rate (panel F). With the nominal interest rate rising by more than inflation, the real interest rate rises causing households to defer consumption (panel D). The decline in consumption lowers output (panel A) and government tax revenues (panel $\mathrm{H}$ ), which leads to a rise in government debt (panel 
B). In subsequent periods, although interest rates are lowered to stimulate the economy and bring it out of recession, government debt is brought back to baseline predominantly through (primary) fiscal surpluses, rather than through a decline in the cost of financing government debt.

In the passive equilibrium (equilibrium A), monetary policy responds to the markup shock by lowering the interest rate, which stimulates consumption and output, raises real marginal costs, and causes inflation to rise by more than it otherwise would. This monetary policy causes tax revenues to rise and leads to a decline in government debt. To stabilize government debt, future policymakers raise the cost of financing government debt, which causes consumption, output, and real marginal costs to decline and places downward pressure on inflation.

It is clear from Figure 1 that monetary policy and the economy's behavior more generally is very different in equilibrium $\mathrm{A}$ than it is in either equilibrium $\mathrm{B}$ or equilibrium $\mathrm{C}$. With these differences in mind, we now apply the equilibrium selection methods described in Section 3 and report the results in Table 2 . To determine whether the equilibria are $\epsilon$-proper, we perturb the model in respect to the information set that private agents use to form expected future aggregate inflation, and replace all instances of $\mathrm{E}_{t} \pi_{t+1}$ in the model with ${ }^{10}$

$$
(1-\epsilon) \mathrm{E}_{t} \pi_{t+1}+\epsilon \mathrm{E}_{t-1} \pi_{t+1}
$$

Table 2 also identifies the equilibria that can be obtained via the iterative Backus and Driffill (1986) and Oudiz and Sachs (1985) solution procedures and shows the average loss associated with each equilibrium.

\begin{tabular}{l|c|c|c}
\hline \multicolumn{4}{c}{ Table 2: Equilibrium characteristics } \\
\hline \multicolumn{1}{c}{ Characteristic } & \multicolumn{3}{c}{ Equilibrium } \\
\hline (1) Average loss & $\mathrm{A}$ & $\mathrm{B}$ & $\mathrm{C}$ \\
\hline (2) IE-stable (Joint) & 2.2252 & 1.9935 & 1.6700 \\
(3) IE-stable (Private sector) & yes & no & yes \\
\hline (4) Self-enforceable & yes & yes & yes \\
(5) Switch to Pareto-preferred $\left(p_{j}+1\right)$ & no & no & yes \\
\hline (6) $\epsilon$-proper & no & no & yes \\
\hline (7) Policy rule implementable & no & no & no \\
\hline (8) Backus-Driffill & yes & no & yes \\
(9) Oudiz-Sachs & no & no & yes \\
\hline \hline
\end{tabular}

${ }^{10}$ This perturbation is a special case of the slightly more general perturbation represented by equation (45). 
The first row of Table 2 reports the average loss associated with each equilibrium. This row shows that the three equilibria can be welfare ranked and that equilibrium $\mathrm{C}$, the equilibrium in which monetary policy is most active in stabilizing output and inflation, is the Pareto-preferred equilibrium. In contrast, equilibrium $\mathrm{A}$, in which monetary policy seeks to stabilize output and inflation by manipulating government debt, performs worst. Clearly, if policymakers and private agents could coordinate, they would prefer to coordinate on equilibrium C.

Interestingly, the results in Table 2 show that the selection criteria do identify and select equilibrium C. Unlike equilibrium A, equilibrium $\mathrm{C}$ is self-enforceable and $\epsilon$-proper. Moreover, unlike equilibrium $\mathrm{B}$, equilibrium $\mathrm{C}$ is both jointly learnable and private-sector learnable. It is notable, however, that the policy rule in equilibrium $\mathrm{C}$ is not implementable, which means that by pursuing the policy associated with equilibrium $\mathrm{C}$ policymakers cannot ensure that the Pareto-preferred equilibria prevails. Instead, the selection criteria suggest that coordination on the Pareto-preferred equilibrium is likely to occur because it be learnable by private agents and consequently self-enforceable.

\subsection{A DSGE model with capital}

Following Woodford (2003, Chapter 5), the economy is populated by households, intermediategood producing firms, final-good producing firms, and a central bank. Households are identical and infinitely lived, choosing consumption, $c_{t}$, labor, $l_{t}$, and nominal holdings of next period bonds, $b_{t+1}$, to maximize expected discounted utility subject to a budget constraint. On the production side, a unit-continuum of monopolistically competitive intermediate-good producing firms, indexed by $\omega \in[0,1]$, produce by combining labor services hired in a perfectly competitive market with their firm-specific capital. These intermediate-good producing firms make labor and investment decisions, seeking to maximize their value subject to their production technology

$$
Y_{t}(\omega)=e^{u_{t}} K_{t}(\omega)^{\alpha} L_{t}(\omega)^{(1-\alpha)}
$$

their capital accumulation equation

$$
I_{t}(\omega)=I\left(\frac{K_{t+1}(\omega)}{K_{t}(\omega)}\right) K_{t}(\omega)
$$

where $I(1)=\delta, I^{\prime}(1)=1$, and $I^{\prime \prime}(1)=\eta$, and a Calvo (1983) price rigidity, where firms that cannot optimally set their price in a given period are assumed to index their price to lagged aggregate inflation (Smets and Wouters, 2003). Profits are aggregated and returned to households (shareholders) in the form of a lump-sum dividend. The final-good producing 
firms purchase intermediate goods, aggregate them into a final good according to a Dixit and Stiglitz (1977) production technology, and sell these final goods in a perfectly competitive market to households and firms to consume and invest, respectively.

After aggregating and log-linearizing about a zero-inflation nonstochastic steady state, the model's constraints and first-order conditions are

$$
\begin{aligned}
\pi_{t} & =\frac{\theta}{1+\theta \beta} \pi_{t-1}+\frac{\beta}{1+\theta \beta} \mathrm{E}_{t} \pi_{t+1}+\frac{(1-\xi)(1-\beta \xi)}{(1+\theta \beta) \xi} m c_{t}+v_{t}, \\
c_{t} & =\mathrm{E}_{t} c_{t+1}-\frac{1}{\sigma}\left(r_{t}-\mathrm{E}_{t} \pi_{t+1}-g_{t}+\mathrm{E}_{t} g_{t+1}\right), \\
k_{t+1} & =\frac{1}{1+\beta} k_{t}+\frac{\beta}{1+\beta} \mathrm{E}_{t} k_{t+2}+\frac{1-\beta(1-\delta)}{(1+\beta) \eta} \mathrm{E}_{t} m s_{t+1}-\frac{1}{(1+\beta) \eta}\left(r_{t}-\mathrm{E}_{t} \pi_{t+1}\right) \\
m c_{t} & =w_{t}-y_{t}+l_{t}, \\
w_{t} & =\chi l_{t}+\sigma c_{t}-g_{t}, \\
y_{t} & =(1-\gamma) c_{t}+\frac{\gamma}{\delta}\left[k_{t+1}-(1-\delta) k_{t}\right], \\
y_{t} & =u_{t}+\alpha k_{t}+(1-\alpha) l_{t}, \\
m s_{t} & =w_{t}-k_{t}+l_{t}
\end{aligned}
$$

where $\beta \in(0,1)$ is the discount factor, $\rho \equiv \frac{1-\beta}{\beta}$ is the discount rate, $\gamma \equiv \frac{\alpha \delta}{\rho+\delta} \frac{\varepsilon-1}{\varepsilon}$ is the steady-state share of investment in output, $\varepsilon>1$ is the steady-state elasticity of substitution between intermediate goods, $\delta \in(0,1)$ is the depreciation rate, and $\eta>0$ is the elasticity of the investment-to-capital ratio with respect to Tobin's q evaluated at steady state (Eichenbaum and Fisher, 2007).

Although the model allows for three stochastic elements: an aggregate consumptionpreference shock, $g_{t}$; an aggregate markup shock, $v_{t}$; and an aggregate technology shock, $u_{t}$, we zero-out $g_{t}$ and $u_{t}$ in order to focus on the policy trade-offs associated with the markup shock, $v_{t}$, which is assumed to evolve over time according to

$$
v_{t+1}=\rho_{v} v_{t}+\epsilon_{v t+1}
$$

where $\rho_{v} \in(-1,1)$ and $\epsilon_{v_{t+1}}$ is i.i.d. distributed with zero mean and finite variance. ${ }^{11}$

The central bank's loss function is assumed to have the form

$$
L_{t}=(1-\beta) \mathrm{E}_{t} \sum_{k=t}^{\infty} \beta^{(k-t)}\left[\pi_{k}^{2}+\frac{(1-\xi)(1-\beta \xi)}{(1+\theta \beta) \xi \varepsilon} y_{k}^{2}\right] \text {. }
$$

\footnotetext{
${ }^{11}$ To parameterize the model, we set the discount factor, $\beta$, to 0.99 , the Calvo price rigidity, $\xi$, to 0.75 , the inflation indexation parameter, $\theta$, to 0.60 , the Cobb-Douglas production function parameter, $\alpha$, to 0.36 , the capital adjustment costs parameter to 6.0 , the labor supply elasticity, $\chi$, to 1 , the elasticity of intertemporal substitution, $\sigma$, to 2 , the depreciation rate, $\delta$, to 0.025 , the elasticity of subititution between goods, $\varepsilon$, to 11 , and the shock persistece, $\rho_{v}$, to 0.3 .
} 
With monetary policy conducted under discretion this model has three symmetric Markovperfect Stackelberg-Nash equilibria. The policy rule and the private-sector decision rules for each equilibria are reported in Table 3.

\begin{tabular}{|c|c|c|c|c|c|c|}
\hline \multicolumn{7}{|c|}{ Table 3: Policy rules in equilibrium } \\
\hline Eqm & $\mathbf{F}=$ & $F_{v} \quad F_{k}$ & $\left.F_{\pi}\right]$ & $\mathbf{H}=$ & $\begin{array}{ll}H_{\pi v} & H_{\pi k} \\
H_{c v} & H_{c k} \\
H_{k v} & H_{k k} \\
\end{array}$ & $\left.\begin{array}{l}H_{\pi \pi} \\
H_{c \pi} \\
H_{k \pi}\end{array}\right]$ \\
\hline $\mathrm{A}$ & {$[-7.0380$} & 10.2219 & -1.2404 & $\begin{array}{l}2.439 \\
2.447 \\
0.658\end{array}$ & $\begin{array}{l}-2.7992 \\
-4.5867 \\
-0.4265\end{array}$ & $\begin{array}{l}0.6261 \\
0.4119 \\
0.1106\end{array}$ \\
\hline $\mathrm{B}$ & {$[1.8248$} & -0.0024 & 1.0199 & $\begin{array}{r}0.3319 \\
-1.554 \\
-0.473\end{array}$ & $\begin{array}{c}-0.1944 \\
0.2006 \\
0.9302\end{array}$ & $\begin{array}{c}0.1075 \\
-0.5847 \\
-0.1711\end{array}$ \\
\hline $\mathrm{C}$ & 1.8651 & -0.0191 & 1.0340 & $\begin{array}{r}0.1683 \\
-1.674 \\
-0.510\end{array}$ & $\begin{array}{c}-0.0051 \\
0.3302 \\
0.9696\end{array}$ & $\begin{array}{c}0.0673 \\
-0.6152 \\
-0.1802\end{array}$ \\
\hline
\end{tabular}

To understand why this model has multiple equilibria we again turn to the Phillips curve and to the problem of stabilizing inflation. Adapting a result from Dennis and Söderström (2006), the forward representation of the inflation equation is given by

$$
\pi_{t}=\theta \pi_{t-1}+\frac{(1-\xi)(1-\beta \xi)}{\xi} \mathrm{E}_{t} \sum_{k=t}^{\infty} \beta^{(k-t)} m c_{k}+\frac{1+\theta \beta}{1-\rho_{v} \beta} v_{t}
$$

Moreover, real marginal costs can be expressed as

$$
\begin{aligned}
m c_{t} & =\alpha m s_{t}+(1-\alpha) w_{t} \\
& =\left(\frac{\alpha+\chi}{1-\alpha}+\frac{\sigma}{1-\gamma}\right) y_{t}+\left[\frac{\sigma \gamma(1-\delta)}{(1-\gamma) \delta}-\frac{\alpha(\alpha+\chi)}{1-\alpha}\right] k_{t}-\frac{\sigma \gamma}{(1-\gamma) \delta} k_{t+1}
\end{aligned}
$$

Analogous to the model with government debt, equation (48) shows that movements in $m c_{t}$ and $m c_{t+1}$ are highly substitutable in terms of their effect on $\pi_{t}$ and that, for any initial value of inflation, there are multiple paths for $m c_{t}$ that will return inflation to target. As earlier, these different paths for real marginal costs are associated with different monetary policies and with different performance in terms of loss. Equation (49) shows that monetary policy can affect $m c_{t}$ through two distinct channels. To lower real marginal costs, the central bank can either raise the real interest rate, weakening aggregate demand and thereby causing $y_{t}$ to decline or it can lower the real interest rate to stimulate investment and thereby boost the future capital stock. Notice that raising (lowering) the real interest rate causes both $y_{t}$ and $k_{t+1}$ to decline (rise) and that $y_{t}$ and $k_{t+1}$ have countervailing effects on $m c_{t}$. As a 
consequence, the desirability of each policy from the perspective of the period- $t$ policymaker turns on how future policymakers are expected to respond to the capital stock.

Consider the case where future policymakers are expected to lower the interest rate in response to a rise in the capital stock. Following a positive markup shock, the policy of raising the real interest rate and causing $y_{t}$ and $k_{t+1}$ to decline will successfully deliver lower real marginal costs and inflation because the boost in future real marginal costs caused by the decline in the capital stock is offset by higher interest rates in the future. Under this approach, monetary policy responds to the positive markup shock by contracting demand, lowering real marginal costs and inflation, and by then lowering interest rates as inflation declines allowing the economy to recover, producing equilibrium $\mathrm{C}$ (or B). Alternatively, if future policymakers are expected to raise the interest rate in response to a higher capital stock, then a policy that lowers the real interest rate and stimulates investment can bring about a decline in inflation, despite the boost to $y_{t}$ and $m c_{t}$ today, because future policymakers respond to the higher capital stock by tightening monetary policy, producing equilibrium A.

The economy's behavior in the different equilibria are shown in Figure 2 which displays the responses of key variables to a unit markup shock.

Focusing first on equilibria $\mathrm{B}$ and $\mathrm{C}$, following the markup shock the interest rate is raised (Panel I) by more than the increase in inflation (Panel F), causing the real interest rate to rise. The higher real interest rate generates a decline in consumption (Panel D) and investment (Panel G), which lowers output (Panel A) and real marginal costs (Panels E and H). Further, the fall in investment leads to a decline in the capital stock (Panel B). In subsequent periods, the decline in real marginal costs causes inflation to moderate. With inflation declining back to baseline, monetary policy responds by lowering the interest rate and stimulating demand. In these two equilibria, monetary policy stabilizes the economy in the traditional way, contracting output and hence real marginal costs in order to keep inflationary pressures contained. 

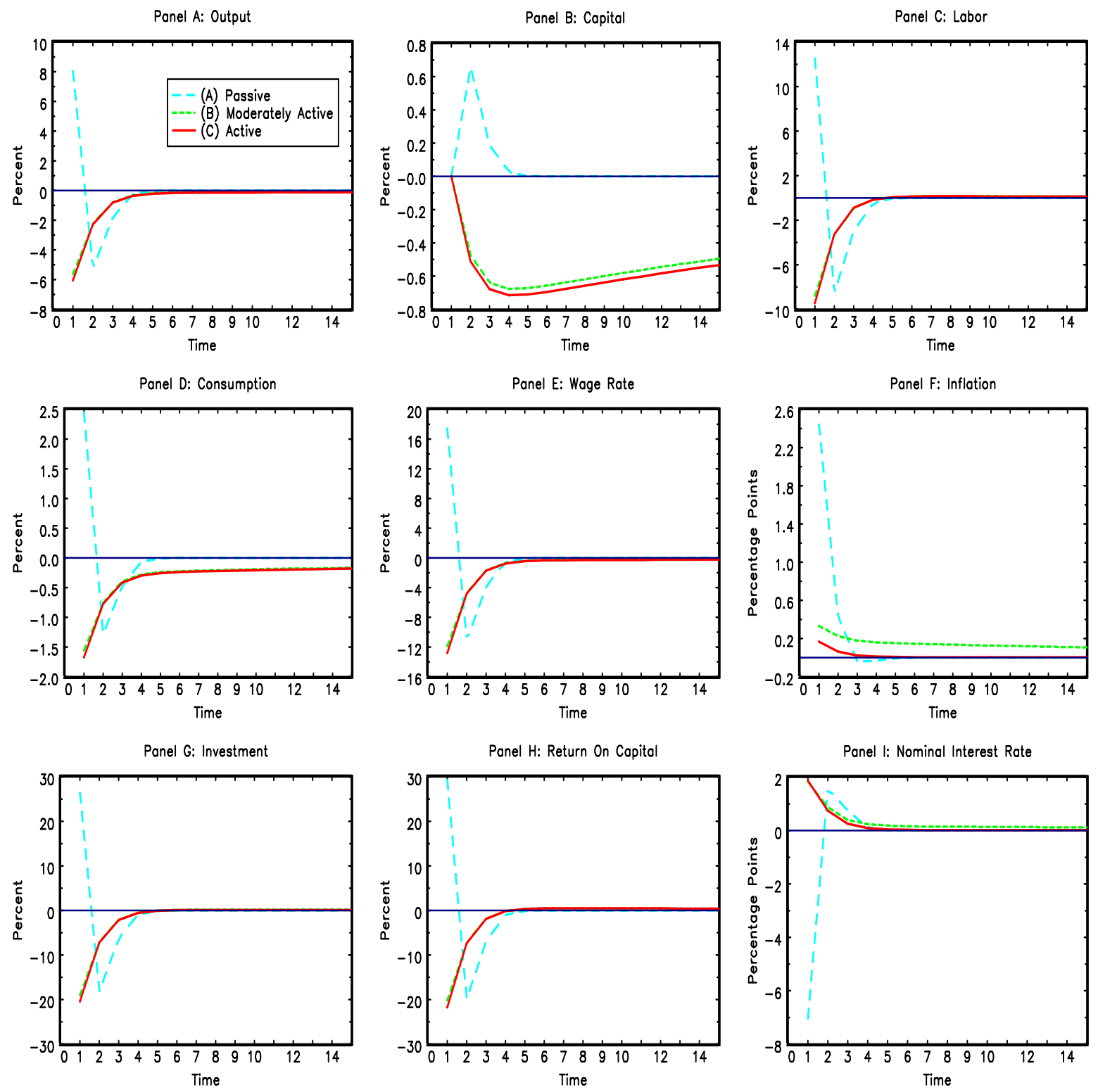

Figure 2: Responses to unit markup shock

In contrast, in equilibrium A the interest rate is lowered in response to the positive markup shock, generating a big decline in the real interest rate. The lower real interest rate stimulates consumption and investment, which pushes up output and real marginal costs and further boosts inflation. However, the rise in investment causes the capital stock to increase and the capital build up eventually lowers real marginal costs while inducing tighter monetary policy. Although the policy tightening is aimed primarily at lowering investment, it also serves to lower output, which causes a further decline in real marginal costs. In this equilibrium, 
monetary policy responds to the markup shock by stimulating the economy in order to boost capital spending. This policy succeeds in stabilizing the economy because the higher capital stock causes future real marginal costs to decline and future monetary policy to tighten.

Clearly the economy behaves very differently in equilibrium A than it does in equilibrium B. But is the conventional policy associated with equilibria $\mathrm{B}$ and $\mathrm{C}$ superior to the unconventional policy associated with equilibrium A and should we expect one equilibrium to prevail over the other? To answer these questions we apply the equilibrium selection methods described in Section 3 and report the results in Table 4. As earlier, to analyze whether the equilibria are $\epsilon$-proper, we perturb the model in respect to the information set that private agents use to form expected future aggregate inflation, see equation (47).

\begin{tabular}{l|c|c|c}
\hline \hline \multicolumn{4}{c}{ Table 4: Equilibrium characteristics } \\
\hline \multicolumn{1}{c|}{ Characteristic } & \multicolumn{3}{c}{ Equilibrium } \\
\hline (1) Average loss & A & B & C \\
\hline (2) IE-stable (Joint) & yes & no & yes \\
(3) IE-stable (Private sector) & yes & yes & yes \\
\hline (4) Self-enforceable & no & no & yes \\
(5) Switch to Pareto-preferred $\left(p_{j}+1\right)$ & 69 & 3 & - \\
\hline (6) $\epsilon$-proper & yes & no & yes \\
\hline (7) Policy rule implementable & no & yes & yes \\
\hline (8) Backus-Driffill & yes & no & yes \\
(9) Oudiz-Sachs & no & no & yes \\
\hline \hline
\end{tabular}

It is clear from Table 4 that the conventional policy is superior to the unconventional policy (row 1). Rows (2) and (3) show that both equilibrium A and equilibrium $\mathrm{C}$ are jointly learnable and learnable by private agents while row (6) shows that these equilibria are both $\epsilon$-proper. However, because the Pareto-preferred equilibrium (equilibrium C) is private-sector learnable, it follows that equilibria A and B are not self-enforceable. Further, it is notable that the policy rule associated with the Pareto-preferred equilibrium is implementable. Accordingly, by conducting policy according to the rule associated with equilibrium $\mathrm{C}$, policymakers can ensure that equilibrium $\mathrm{C}$ prevails. Like the previous model, therefore, the Pareto-preferred equilibrium is selected as the equilibrium of interest.

\section{Conclusion}

Discretionary policymakers can manage neither the expectations of private agents nor the actions of future policymakers. As a consequence, discretionary policymakers are susceptible 
to expectations traps and coordination failures and discretionary control problems can have multiple equilibria. Recognizing this potential for multiple equilibria, this paper addresses the important issue of equilibrium selection, an issue related intrinsically to the capacity for agents to coordinate. One contribution of this paper is to cast the discretionary control problem as a dynamic game, allowing us to explain clearly the strategic interactions that give rise to multiple equilibria. However, the paper's main contribution is to develop a range of equilibrium selection criteria, criteria motivated by expectational stability, self-enforceability, and a notion of properness.

We illustrate these equilibrium selection criteria by applying them to two New Keynesian models. In the first model, the Pareto-preferred equilibrium is one of two equilibria that is both jointly learnable and learnable by private agents. Since, the Pareto-preferred is the only equilibrium that is self-enforceable and $\epsilon$-proper in this model, the equilibrium selection criteria indicate that agents might plausibly coordinate upon it. In the second model, the Pareto-preferred equilibrium is one of two equilibrium that is jointly learnable and $\epsilon$-proper, and all equilibria are private sector learnable. Nevertheless, the Pareto-preferred equilibrium is selected as the equilibrium of interest because it is self-enforceable and because it is implementable.

Although these selection criteria happen to point to the Pareto-preferred equilibrium as the equilibrium of interest in these two models, this need not have been the case. Our experience is that the Pareto-preferred equilibrium is jointly learnable, but that it is not necessarily private sector learnable. It is entirely possible, therefore, that in other models these selection criteria could point toward equilibria (or an equilibrium) that is Pareto-dominated. Finally, while we have described and applied three selection criteria in this paper, there are, of course, other approaches to selecting among equilibria. One such approach might be to select an equilibrium using minimax-loss or minimax-regret; another might be to identify an equilibrium from the limiting behavior of quasi-commitment policies. We leave the study and application of these criteria, and an investigation into whether multiple discretionary equilibria is a general feature of New Keynesian monetary policy models, for future work.

\section{References}

[1] Albanesi, S., Chari, V., and L. Christiano, (2003), "Expectation Traps and Monetary Policy," Review of Economic Studies, 70, pp. 715-741.

[2] Anderson, E., Hansen, L., McGrattan, E., and T. Sargent, (1996), "Mechanics of Forming and Estimating Dynamic Linear Economies" in Amman, H., Kendrick, D., and J. Rust 
(eds) Handbook of Computational Economics, Volume 1, Chapter 4, North Holland, New York.

[3] Backus, D., and J. Driffill, (1986), "The Consistency of Optimal Policy in Stochastic Rational Expectations Models," Centre for Economic Policy Research Discussion Paper \#124.

[4] Barro, R., and D. Gordon, (1983), "Rules, Discretion and Reputation in a Model of Monetary Policy," Journal of Monetary Economics, 12, pp. 101-121.

[5] Benhabib, J., and R. Farmer, (1999), "Indeterminacy and Sunspots in Macroeconomics," in Taylor, J., and M. Woodford, (eds), Handbook of Macroeconomics, Elsevier, Chapter 6, pp. 387-448.

[6] Bernheim, D., Peleg, B., and M. Whinston, (1987), "Coalition-Proof Nash Equilibria: I. Concepts," Journal of Economic Theory, 42, pp. 1-12.

[7] Bernheim, D., and M. Whinston, (1987), "Coalition-Proof Nash Equilibria: II. Applications," Journal of Economic Theory, 42, pp.13-29.

[8] Blake, A., and T. Kirsanova, (2007), "Discretionary Policy and Multiple Equilibria in LQ RE Models," University of Exeter Working Paper.

[9] Calvo, G., (1983), "Staggered Contracts in a Utility-Maximising Framework," Journal of Monetary Economics, 12, pp. 383-398.

[10] Chari, V., and P. Kehoe, (1990), "Sustainable Plans," Journal of Political Economy, 98, 4, pp. 783-802.

[11] Christiano, L., Eichenbaum, M., and C. Evans, (2005), "Nominal Rigidities and the Dynamic Effects of a Shock to Monetary Policy," Journal of Political Economy, 113, pp. $1-45$.

[12] Chow, G., (1997), Dynamic Economics: Optimization by the Lagrange Method, Oxford University Press, Oxford.

[13] Clarida, R., Galí, J., and M. Gertler, (1999), "The Science of Monetary Policy: A New Keynesian Perspective," Journal of Economic Literature, 37, pp. 1661-1707.

[14] Clements, D., and H. Wimmer, (2003), "Existence and Uniqueness of Unmixed Solutions of the Discrete-Time Algebraic Riccati Equation," Systems Control Letters, 50, pp. 343346.

[15] Cohen, D., and P. Michel, (1988), "How Should Control Theory be Used to Calculate a Time-Consistent Government Policy?" Review of Economic Studies, 55, pp. 263-274.

[16] Cooper, R., and A. John, (1988), "Coordination Failures in New Keynesian Models," The Quarterly Journal of Economics, 103, 3, pp. 441-463.

[17] Currie, D. and P. Levine, (1985), "Optimal Feedback Rules in an Open Economy Macromodel with Rational Expectations," European Economic Review, 27, pp. 141-163.

[18] Currie, D. and P. Levine, (1993), "Rules, Reputation and Macroeconomic Policy Coordination," Cambridge University Press, Cambridge, UK.

[19] Davig, T., and E. Leeper, (2006), "Fluctuating Macro Policies and the Fiscal Theory," in NBER Macroeconomics Annual, MIT Press.

[20] Dennis, R., and U. Söderström, (2006), "How Important is Precommitment for Monetary Policy?" Journal of Money, Credit, and Banking, 38, 4, pp. 847-872. 
[21] de Zeeuw, A., and F. van der Ploeg, (1991), "Difference Games and Policy Evaluation: A Conceptual Framework," Oxford Economic Papers, 43, 4, pp. 612-636.

[22] Dixit, A., and J. Stiglitz, (1977), "Monopolistic Competition and Optimum Product Diversity," American Economic Review Papers and Proceedings, 67, pp. 297-308.

[23] Dotsey, M., and A. Hornstein, (2008), "On the Implementation of Markov-Perfect Interest Rate and Money Supply Rules: Global and Local Uniqueness," Federal Reserve Bank of Philadelphia Working Paper \#08-30.

[24] Eichenbaum, M., and J. Fisher, (2007), "Estimating the Frequency of Price Reoptimization in Calvo-Style Models," Journal of Monetary Economics, 54, pp. 2032-2047.

[25] Evans, G., (1985), "Expectational Stability and the Multiple Equilibria Problem in Linear Rational Expectations Models," The Quarterly Journal of Economics, 100, 4, pp. 12171233.

[26] Evans, G., (1986), "Selection Criteria for Models with Non-Uniqueness," Journal of Monetary Economics, 18, pp. 147-157.

[27] Evans, G., (2001), "Expectations in Macroeconomics: Adaptive versus Eductive Learning," Revue Economique, 52, 3, pp. 573-582.

[28] Evans, G., R. Guesnerie, (1993), "Rationalizability, Strong Rationality, and Expectational Stability," Games and Economic Behavior, 5, pp. 632-646.

[29] Evans, G., R. Guesnerie, (2003), "Coordination on Saddle-Path Solutions, The Eductive Viewpoint: Linear Univariate Models," Macroeconomic Dynamics, 7, pp. 42-62.

[30] Evans, G., and R. Guesnerie, (2005), "Coordination on Saddle-Path Solutions: The Eductive Viewpoint - Linear Multivariate Models," Journal of Economic Theory, 124, pp. 202229 .

[31] Evans, G., and S. Honkapohja, (2001), Learning and Expectations in Macroeconomics, Princeton University Press, Princeton.

[32] Guesnerie, R., and M. Woodford, (1992), "Endogenous Fluctuations," in Laffont, J-J. (ed), Advances in Economic Theory, Cambridge University Press, Cambridge.

[33] Ireland, P., (1997), "Sustainable Monetary Policies," Journal of Economic Dynamics and Control, 22, pp. 87-108.

[34] Jensen, H., (2002), "Targeting Nominal Income Growth or Inflation?" American Economic Review, 92, 4, pp. 928-956.

[35] Kurozumi, T., (2008), "Optimal Sustainable Monetary Policy," Journal of Monetary Economics, 55 , pp. $1277-1289$.

[36] King, R., and A. Wolman, (2004), "Monetary Discretion, Pricing Complementarity, and Dynamic Multiple Equilibria," The Quarterly Journal of Economics, 199, 4, pp. 15131553.

[37] Kydland, F., and E. Prescott, (1977), "Rules Rather Than Discretion: The Inconsistency of Optimal Plans," Journal of Political Economy, 87, pp. 473-492.

[38] Laub, A., (1979), "A Schur Method for Solving Algebraic Riccati Equations," IEEE Transactions on Automatic Control, 24, pp. 913-921.

[39] Leeper, E., (1991), "Equilibria under 'Active' and 'Passive' Monetary and Fiscal Policies," Journal of Monetary Economics, 27, pp. 127-147. 
[40] Lucas, R., and N. Stokey, (1983), "Optimal Fiscal and Monetary Policy in an Economy Without Capital," Journal of Monetary Economics, 12, pp. 55-93.

[41] McCallum, B., (2007), "E-Stability vis-a-vis Determinacy Results for a Broad Class of Linear Rational Expectations Models," Journal of Economic Dynamics and Control, 31, pp. 1376-1391.

[42] Magnus, J., and H. Neudecker, (1988), Matrix Differential Calculus with Applications to Statistics and Econometrics, John Wiley and Sons, New York.

[43] Marcet, A., and T. Sargent, (1989), "Convergence of Least Squares Learning Mechanisms in Self-Referential Linear Stochastic Models," Journal of Economic Theory, 48, pp. 337368.

[44] Myerson, R., (1978), "Refinements of the Nash Equilibrium Concept," International Journal of Game Theory, 7, pp. 73-80.

[45] Oudiz, G., and J. Sachs, (1985), "International Policy Coordination in Dynamic Macroeconomic Models," in Buiter, W., and R. Marston, (eds), International Economic Policy Coordination, Cambridge University Press, Cambridge, pp. 275-319.

[46] Ortigueira, S., and J. Pereira, (2009), "Markov-Perfect Optimal Fiscal Policy: The Case of Unbalanced Budgets," manuscript.

[47] Rogoff, K., (1985), "The Optimal Degree of Commitment to an Intermediate Monetary Target," The Quarterly Journal of Economics, 100, 4, pp. 1169-1189.

[48] Smets, F., and R. Wouters, (2003), "An Estimated Stochastic Dynamic General Equilibrium Model of the Euro Area," Journal of the European Economic Association, 1, 5, pp. 1123-1175.

[49] Smets, F., and R. Wouters, (2007), "Shocks and Frictions in US Business Cycles: A Bayesian DSGE Approach," American Economic Review, 97, 3, pp. 586-606.

[50] Sveen, T., and L. Weinke, (2007), "Firm-Specific Capital, Nominal Rigidities, and the Taylor Principle," Journal of Economic Theory, 136, pp. 729-737.

[51] van Zandweghe, W., and A. Wolman, (2010), "Discretionary Monetary Policy in the Calvo Model," Federal Reserve Bank of Kansas City Working Paper \#10-06.

[52] Walsh, C., (1995), "Optimal Contracts for Central Bankers," American Economic Review, 85,1 , pp. $150-167$.

[53] Walsh, C., (2003), "Speed Limit Policies: The Output Gap and Optimal Monetary Policy," American Economic Review, 93, 1, pp. 265-278.

[54] Woodford, M., (2003), Interest and Prices: Foundations of a Theory of Monetary Policy, Princeton University Press, Princeton, New Jersey. 